\title{
Assessment of an ensemble of ocean-atmosphere coupled and uncoupled regional climate models to reproduce the climatology of Mediterranean cyclones
}

\author{
Emmanouil Flaounas ${ }^{1} \cdot$ Fanni Dora Kelemen $^{2} \cdot$ Heini Wernli $^{3} \cdot$ Miguel Angel Gaertner $^{4} \cdot$ \\ Marco Reale ${ }^{5} \cdot$ Emilia Sanchez-Gomez $^{6} \cdot$ Piero Lionello $^{7,12} \cdot$ Sandro Calmanti $^{8} \cdot$ Zorica Podrascanin $^{9}$. \\ Samuel Somot ${ }^{10} \cdot$ Naveed Akhtar $^{11} \cdot$ Raquel Romera $^{4} \cdot$ Dario Conte $^{12}$
}

Received: 13 April 2016 / Accepted: 9 October 2016 / Published online: 4 November 2016

(C) The Author(s) 2016. This article is published with open access at Springerlink.com

\begin{abstract}
This study aims to assess the skill of regional climate models (RCMs) at reproducing the climatology of Mediterranean cyclones. Seven RCMs are considered, five of which were also coupled with an oceanic model. All simulations were forced at the lateral boundaries by the ERA-Interim reanalysis for a common 20-year period (1989-2008). Six different cyclone tracking methods have been applied to all twelve RCM simulations and to the ERA-Interim reanalysis in order to assess the RCMs from the perspective of different cyclone definitions. All RCMs reproduce the main areas of high cyclone occurrence in the region south of the Alps, in the Adriatic, Ionian and
\end{abstract}

This paper is a contribution to the special issue on MedCORDEX, an international coordinated initiative dedicated to the multi-component regional climate modelling (atmosphere, ocean, land surface, river) of the Mediterranean under the umbrella of HyMeX, CORDEX, and Med-CLIVAR and coordinated by Samuel Somot, Paolo Ruti, Erika Coppola, Gianmaria Sannino, Bodo Ahrens, and Gabriel Jordà.

Electronic supplementary material The online version of this article (doi:10.1007/s00382-016-3398-7) contains supplementary material, which is available to authorized users.

Emmanouil Flaounas

flaounas@noa.gr

National Observatory of Athens, Athens, Greece

2 Institute for Geophysics and Meteorology, University of Cologne, Cologne, Germany

3 Institute for Atmospheric and Climate Science, ETH Zurich, Zurich, Switzerland

4 University of Castilla-La Mancha, Toledo, Spain

5 OGS (Istituto Nazionale di Oceanografia e Geofisica Sperimentale), Borgo Grotta Gigante, Sgonico (TS), Italy

6 CERFACS/SUC, URA1875, Toulouse, France
Aegean Seas, as well as in the areas close to Cyprus and to Atlas mountains. The RCMs tend to underestimate intense cyclone occurrences over the Mediterranean Sea and reproduce $24-40 \%$ of these systems, as identified in the reanalysis. The use of grid nudging in one of the RCMs is shown to be beneficial, reproducing about $60 \%$ of the intense cyclones and keeping a better track of the seasonal cycle of intense cyclogenesis. Finally, the most intense cyclones tend to be similarly reproduced in coupled and uncoupled model simulations, suggesting that modeling atmosphereocean coupled processes has only a weak impact on the climatology and intensity of Mediterranean cyclones.

\section{Introduction}

The Mediterranean region (MR, Fig. 1) is located in a transition zone between arid North Africa and the North Atlantic storm tracks. Regional atmospheric dynamics are strongly influenced by the Mediterranean Sea, the surrounding high mountains and the sharp land-sea transitions.

Department of Science and Technology for Biology and Environment, University of Salento, Lecce, Italy

8 ENEA, Rome, Italy

9 Department of Physics, Faculty of Sciences, University of Novi Sad, Novi Sad, Serbia

10 CNRM, UMR3589, Météo-France and CNRS, Toulouse, France

11 Institute for Atmospheric and Environmental Sciences, Goethe University, Frankfurt Am Main, Germany

12 CMCC, Euro-Mediterranean Center on Climate Change, Lecce, Italy 
Fig. 1 The Mediterranean domain that has been used for the cyclone tracking (black box). The shading indicates terrain elevation (in $\mathrm{m}$ ). The grey thick line depicts the subjectively drawn track of the December 2005 medicane, using the SLP from ERAI. The colored lines show the medicane tracks, as diagnosed by the different tracking methods (described in the Appendix)

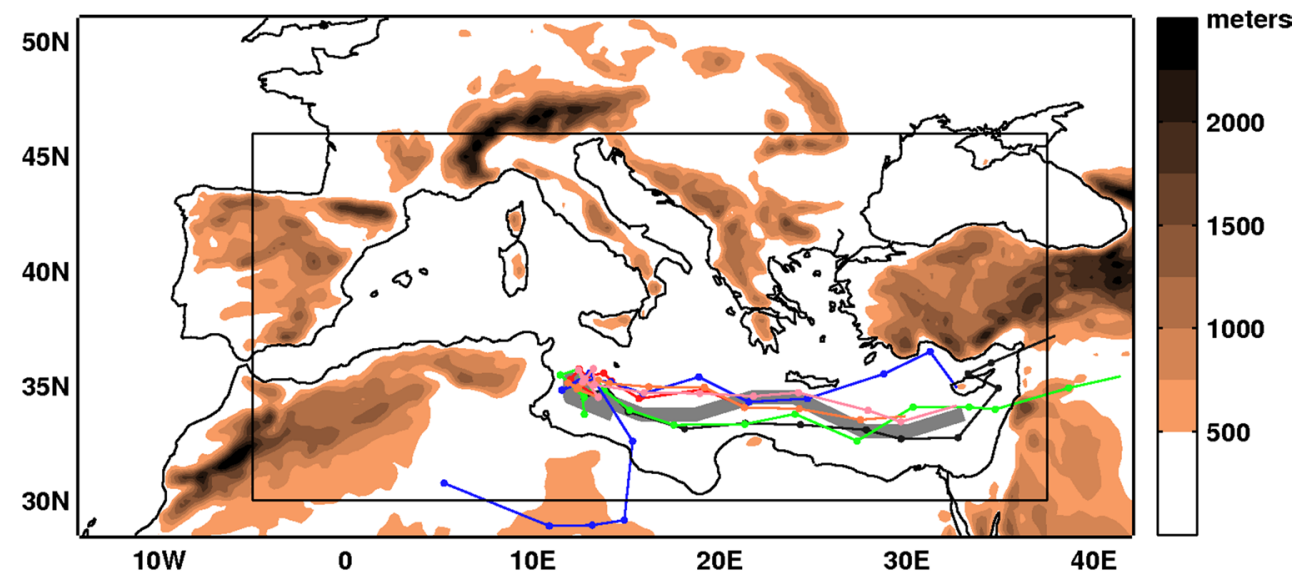

\begin{tabular}{|lllll|l|l|l} 
ERAI & M1 & M2 & M3 & M5 & M6
\end{tabular}
In such a unique environment, cyclogenesis is frequent, placing the Mediterranean among the regions with the highest occurrence of cyclones in the world (Neu et al. 2013).

Intense cyclones in the MR mainly form due to synoptic scale atmospheric systems, such as upper-tropospheric Rossby waves and stratospheric air intrusions (Fita et al. 2006; Claud et al. 2010; Flaounas et al. 2015a). They mainly occur in winter and autumn and they are favored at the leeward side of the Alps and Atlas Mountains, over the Gulf of Lions, the Ionian, Adriatic and Aegean Seas (e.g., Alpert et al. 1990; Trigo et al. 1999; Maheras et al. 2001; Campins et al. 2011; Lionello et al. 2016). These cyclones have a strong impact on the Mediterranean climate, its variability and extremes (e.g., Trigo et al. 2000; Lionello et al. 2006; Gaertner et al. 2007; Lionello and Giorgi 2007; Walsh et al. 2014; Zappa et al. 2015). Indeed, several studies showed the significant contribution of cyclones to the majority of rainfall and wind extremes (e.g., Jansà et al. 2001; Nissen et al. 2010; Reale and Lionello 2013; RavehRubin and Wernli 2015), to the formation of the most prominent high impact weather events (Llasat et al. 2010), as well as to the modulation of the Mediterranean hydrological cycle (Romanski et al. 2012; Flaounas et al. 2015b).

Given their importance to the Mediterranean climate, cyclones proper representation by models is crucial for studying climate dynamics and impacts. To this end, reanalysis data is considered to provide realistic results due to the assimilation of a plethora of observations into atmospheric models. However, global reanalyses are typically available with relatively coarse resolutions that prohibit the detailed reproduction of cyclone meso-scale dynamics and weather extremes. To address this issue, RCMs have been long ago employed to analyze climate dynamics across different spatial scales (e.g., Giorgi 1990; Deque and Piedelievre 1995). In fact, several recent studies demonstrated the benefits from the use of RCMs in reproducing climate patterns at local scales within the MR and for improving the quality of input data for impact studies in areas of complex geography (Flaounas et al. 2013; Guyennon et al. 2013; D’Onofrio et al. 2014; Calmanti et al. 2015). Despite their ability to resolve fine-scale atmospheric features, RCM results are associated with significant uncertainties. For instance, RCMs are known to be particularly sensitive to the physical parameterization of atmospheric processes, to the boundary conditions, horizontal/vertical resolution (e.g., Roeckner et al. 2006; Sanchez-Gomez et al. 2011; Herrmann et al. 2011; Flaounas et al. 2011; Di Luca et al. 2014), and internal variability (e.g., Christensen et al. 2001; Sanchez-Gomez and Somot, 2016). Especially the latter is a primary source of uncertainty and leads to spread in RCM behavior under the same external conditions.

One of the specific objectives of the Coordinated Regional Downscaling Experiment (CORDEX) initiative is to provide a coordinated framework for the systematic investigation of RCM uncertainties in order to provide meaningful atmospheric data on fine scales (Giorgi et al. 2009). The MED-CORDEX initiative is the declination of CORDEX devoted to the MR (www.medcordex.eu; Ruti et al. 2015). In line with the objectives of CORDEX, in this study we assess the capacity of twelve RCM simulations to realistically reproduce Mediterranean cyclones, especially the most intense systems, which are also expected to provoke the majority of regional climate extremes and the strongest socio-economic impacts. These simulations are produced by seven different models, where two models have been used as stand-alone atmospheric RCMs, while the other five have been used both as atmospheric RCMs and as interactively coupled RCMs with oceanic models.

This study aims first at contributing to the better understanding of RCM deficiencies when used for climatological studies on cyclone-related impacts and dynamics. Second, 
this study assesses the capacity of RCMs to realistically reproduce intense Mediterranean cyclones, and finally it investigates the potential added value in using coupled models for reproducing intense Mediterranean cyclones. The RCMs assessment is achieved by comparing their cyclone climatologies to the one produced by the reanalysis, which also provided the RCMs initial and lateral boundary atmospheric conditions. The next section presents the models and the cyclone tracking methods. Section 3 provides a cyclone climatology comparison between ERAInterim (ERAI; Dee et al. 2011) and the MED-CORDEX models and finally, in Sect. 4 we summarize our methods and results, and present the main conclusions of this study.

\section{Models, cyclone tracking and methodology}

\subsection{Regional climate models and tracking methods}

All simulations used in this study have been performed within the framework of MED-CORDEX, for the period 1989-2008 and their domains cover the broader MR with small variations in their size. The RCMs initial and lateral boundary conditions have been taken from ERAI at a grid spacing of $0.75^{\circ} \times 0.75^{\circ}$ in longitude and latitude, every $6 \mathrm{~h}$. The time varying field of sea surface temperature (SST) was also taken from ERAI for the uncoupled simulations. In addition, the simulations for five RCMs have been repeated with the SST fields explicitly calculated by coupled high-resolution regional oceanic models. All RCMs included in this study present a variety of different characteristics such as different horizontal resolutions, number of vertical levels and physical parameterizations. In particular, the WRF model is the only model that applies grid nudging to wind, temperature and water vapor on all atmospheric levels except of those within the planetary boundary layer. Table 1 presents the details and references of the simulations and models used in this study.

To identify and track cyclones, six different cyclone tracking methods have been applied, based on either sea level pressure (SLP) or relative vorticity at $850 \mathrm{hPa}(\mathrm{RV})$, i.e., the two atmospheric fields that are commonly used for tracking cyclones in gridded datasets (Hoskins and Hodges 2002; Neu et al. 2013). SLP is a low frequency field that reflects the atmospheric mass distribution, and is representative mainly of synoptic-scale atmospheric processes. On the other hand, relative vorticity is a high frequency field that is representative of the atmospheric circulation. Method 1 (Flaounas et al. 2014) and method 2 (Ayrault and Joly 2000) are both RV-based methods, identifying cyclones as local maxima of RV at $850 \mathrm{hPa}$. Methods 3-6 are all based on SLP. In particular, method 3 (Kelemen et al. 2015) and method 6 (Picornell et al. 2001) identify cyclones as local SLP minima, while method 4 (Lionello et al. 2002; Reale and Lionello 2013) and method 5 (Wernli and Schwierz 2006) perform a processing of SLP fields prior to determining cyclone centers as local SLP minima. All methods are described in detail in the Appendix and have been previously applied in the MR, among other methods that were used to study the MR climatology of cyclones (e.g., Murray and Simmonds 1991; Trigo et al. 1999; Pinto et al. 2005; Bartholy et al. 2009; Campins et al. 2011). Our motivation in using a variety of cyclone tracking methods is the fact that their results may present significant variability, even when considering same periods and input datasets (e.g., Bartholy et al. 2009; Campins et al. 2011; Lionello et al. 2016). Uncertainties exist due to differences in the mathematical and physical definitions of cyclones among the methods, as well as due to the tracking tools' sensitivity to several factors such as the horizontal grid spacing of the input datasets (Kouroutzoglou et al. 2011; Hanley and Caballero 2012; Rudeva et al. 2014). The sensitivity of extratropical cyclone climatologies due to the use of different tracking methods has been thoroughly analyzed within the framework of the IMILAST project (Neu et al. 2013), while Lionello et al. (2016) specifically addressed this question for the MR.

Figure 1 provides an example of the uncertainty in cyclone tracking due to the use of different tracking methods. It illustrates the tracks of a medicane (merging of the words Mediterranean Hurricane) that occurred in December 2005 (Fita et al. 2007). The tracks are calculated by the six tracking methods, applied to ERAI, and are compared to the manually analyzed track, by connecting the ERAI local SLP minima at consecutive times. It is evident that methods present a common part of their tracks with the reference, i.e., they all succeeded to capture the cyclone's eastwards displacement over the Mediterranean Sea. However, the lifetime (equivalent to the number of track points), the initial and final location, as well as the cyclone's exact path differ from method to method. The use of multiple tracking methods constitutes an added value permitting the interpretation of RCM performances in reproducing cyclone tracks from different physical perspectives (Neu et al. 2013).

For the assessment of the models' capacity to reproduce the Mediterranean cyclone climatology, we use the ERAI reanalysis as a reference. Therefore, we assess the realistic reproduction of the cyclone tracks by the RCMs, as well as the divergence of their results with respect to the driving dataset. In order to perform a meaningful and fair intercomparison between the models and ERAI, all 6-hourly RCM outputs of SLP and wind (used to calculate relative vorticity) have been upscaled to the ERAI grid (at $0.75^{\circ}$ spatial resolution). Upscaling regional models is opposed to the motivation of performing climate downscaling, however it provides a straightforward and fair intercomparison 
Table 1 Short descriptions of the regional climate model simulations

Atmospheric model
IPSL-WRF311 WRF version 3.1.1 (Skamarock and Klemp 2008) model
at $20 \mathrm{~km}$ horizontal resolution and 28 vertical levels. Grid nudging is
applied on wind, water vapor and temperature to relax WRF outputs
each $6 \mathrm{~h}$ towards ERAI. Among the different physical parametriza-
tions offered by the model, here we use the Kain-Fritsch convection
scheme (Kain 2004), the WSM5 microphysics scheme (Hong et al.
2004) and the RRTMG longwave and shortwave radiation scheme
(Clough et al. 2005)
ENEA-REGCM3 RegCM version 3 (Giorgi and Mearns 1999; Pal et al.
2007) model at $30 \mathrm{~km}$ horizontal resolution and 18 vertical levels

University of Frankfurt-COSMO-CLM CCLM version 4.21 (Rockel et al. 2008) is used for atmospheric-only simulations with horizontal grid resolution of $50 \mathrm{~km}$ and 32 vertical levels

\footnotetext{
University of Belgrade-EBU EBU (Eta Belgrade University) model (a version of NCEP's ETA model) at $0.33^{\circ}(\sim 50 \mathrm{~km})$ horizontal resolution and 26 vertical levels
}

CNRM-ALADIN52 ALADIN-Climate RCM version 5.2 (Colin et al. 2010; Herrmann et al. 2011). The Med-Cordex simulations, used in the current study, are described in details in Tramblay et al. (2013). They have $50 \mathrm{~km}$ horizontal resolution and 31 vertical levels

CMCC-CCLM COSMO-CLM version 4-8-19 (Rockel and Geyer 2008) No coupled simulation model with $50 \mathrm{~km}$ horizontal resolution and 45 vertical levels. Type of convection parameterization: Tiedtke scheme

UCLM-PROMES PROMES version (Domínguez et al. 2010) with $50 \mathrm{~km}$ horizontal resolution and 37 vertical levels
Coupled model version

IPSL-WRF311NEMO The WRF atmospheric model coupled with the oceanic model NEMO (Drobinski et al. 2012; Lebeaupin Brossier et al. 2013)

ENEA-PROTHEUS Composed of RegCM and the MITgcm developed by Marshall et al. (1997a, b) and validated over the Mediterranean area by Sannino et al. (2009). RegCM3 receives the instantaneous values of SST every $6 \mathrm{~h}$. The MITgcm receives from RegCM3 the 6-hourly cumulated rainfall and the surface forcing fields for the ocean, i.e. wind stress, sensible heat flux, latent heat flux, long and short wave incident radiation (Artale et al. 2010)

COSMO-CLM/NEMO-MED12 The coupled model consisted of the atmospheric model CCLM and the ocean model NEMO-MED12. NEMO-MED12 is the regional part of the global ocean model NEMO v3.2, specially tuned for the Mediterranean Sea (for more details see, e.g., Lebeaupin Brossier et al. 2011; Akhtar et al. 2014)

University of Belgrade-EBU/POM EBU-POM is atmospheric-ocean two-way coupled regional model, with the atmospheric component EBU and the ocean component POM (Princeton ocean model). Models exchange atmospheric surface fluxes and SST every atmospheric model time step, which is of the order of minutes (Djurdjevic and Rajkovic 2008; Krzic et al. 2011)

CNRM-RCSM4 The coupled version of CNRM-ALADIN52 described in Sevault et al. (2014) and Nabat et al. (2015) with NEMOMED8 for the ocean, ISBA for the land surface and TRIP for the rivers

No coupled simulation of cyclone climatologies between RCMs and ERAI (Kouroutzoglou et al. 2011). Upscaling RCM fields (with resolutions of 20-50 km; Table 1) is expected to have a detrimental impact only on the detection of small and weak cyclonic features with characteristic lengths inferior to $\sim 80 \mathrm{~km}$ (this is the average $0.75^{\circ} \times 0.75$ grid spacing in the Mediterranean region). Such cyclonic systems unlikely have a strong impact on climate dynamics and extremes.

Cyclone intensity for the RV-based methods 1 and 2 is measured by the maximum RV in the cyclone center. However, methods 1 and 2 apply data filtering before identifying cyclones and hence their cyclone intensity measures are not directly comparable to the other methods. To overcome this inconsistency, the cyclone track points from methods 1 and 2 have been re-attributed to the raw relative vorticity values of the RCM simulations (after regridding to the ERAI grid). For SLP-based methods 3-6, cyclone intensity is determined by the minimum central SLP value along the cyclone track. All six tracking methods are applied to all RCM outputs, as well as to ERAI for the 20-year period of 1989-2008 and within the domain shown in Fig. 1. For all methods, we retain only the cyclones that exist for at least one day (i.e., tracks with at least five 6-hourly track points), as also done in Neu et al. (2013).

\subsection{Using a multi-method approach for tracking cyclones}

The 20-year ERAI Mediterranean cyclone climatology, as reproduced by the six different tracking methods, is shown in Fig. 2 in the form of maps of cyclone center densities (CCD; Neu et al. 2013). The CCD is defined by the frequency of occurrence of cyclone centers within an area of $500 \mathrm{~km}^{2}$ in a given 6-hourly time step. Percentages higher than $100 \%$ denote the existence of more than one cyclone in average in an area of $500 \mathrm{~km}^{2}$ per time step. 
(A) Method 1

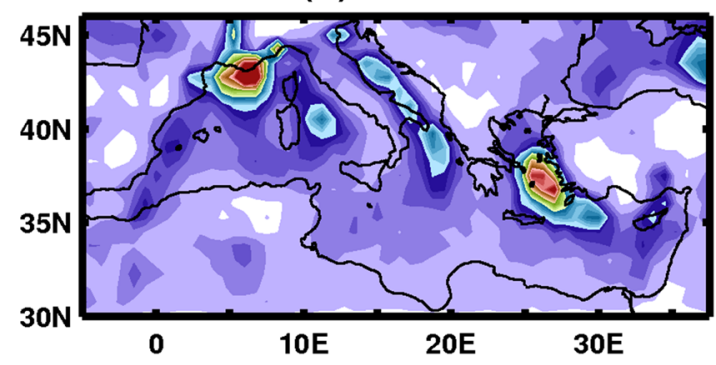

(C) Method 3

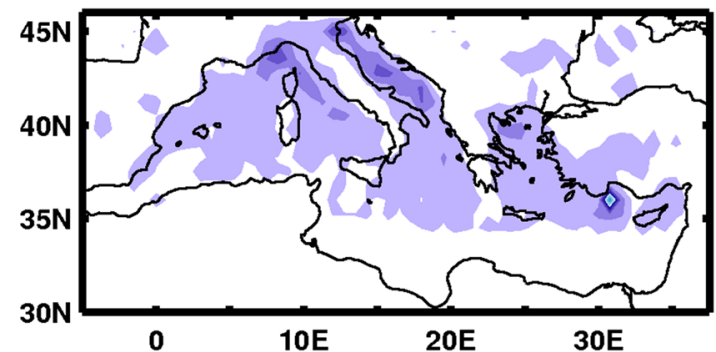

(E) Method 5

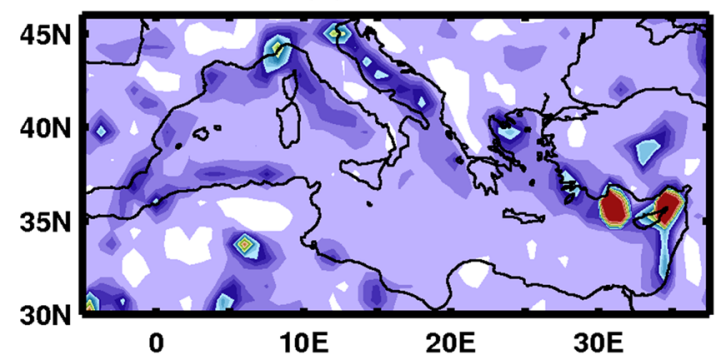

(B) Method 2

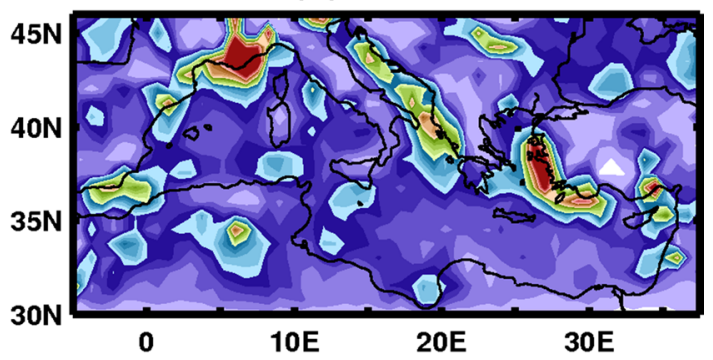

(D) Method 4

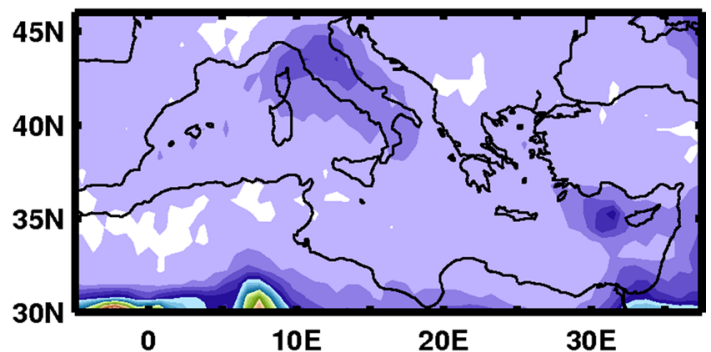

(F) Method 6

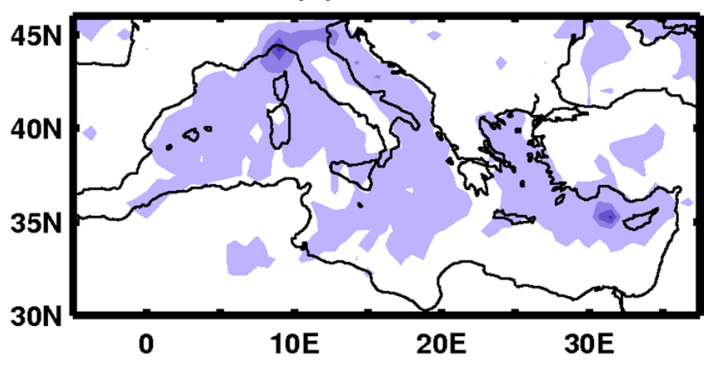

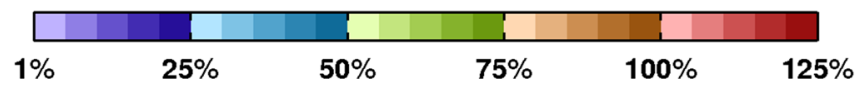

Fig. 2 Cyclone center density as diagnosed by the six different tracking methods during the whole period 1989-2008 in ERAI. White areas correspond to values of less than $1 \%$

The RV-based methods 1 and 2 (Fig. 2a, b) tend to identify more cyclone centers than the SLP-based methods 3-6 (Fig. 2c-f). All methods capture fairly well the main "hot spots" of Mediterranean cyclones over the leeward side of the Alps, over the Adriatic and Aegean Seas, and near Cyprus (Trigo et al. 1999; Campins et al. 2011). The Ionian Sea is also known to present a high concentration of cyclones, however in contrast to the other methods, methods 4 and 6 show no distinct hot spot of CCD in this area. It is noteworthy that the CCD maximum south of the Alps and near Cyprus are located more to the west in the RVbased methods, compared to SLP-based methods. This is mainly due to wind steering at the mountain flanks, which tends to displace the RV local maxima to the west. On the other hand, SLP-based methods may capture the SLP minima also over the mountains, where surface pressure is extrapolated to sea level. The Northwest African cyclones, known as Sharav cyclones, which form near the Atlas mountain chain (Ammar et al. 2014), are also captured by methods 1,2 and 5, while method 4 presents no particular local maximum of CCD in this area. Method 3 uses a spatial filtering that excludes the domain boundary grid points. Consequently, most of North Africa is not taken into account by this method (see Appendix). Table 2 shows significant differences in the number of cyclones captured by each method when applied to ERAI. Differences in cyclone numbers may not be regarded as a token of good or poor skill of a cyclone tracking method, but it rather shows that the cyclone number depends significantly on the adopted physical definition of a cyclone by each method.

Figure 3a shows the cumulative distribution functions of cyclone lifetime in ERAI and Fig. 3b shows the cumulative 
Table 2 The number of cyclones tracked by each method for the uncoupled (first row in each cell) and coupled models (second row in each cell)

\begin{tabular}{|c|c|c|c|c|c|c|c|c|}
\hline Tracking method & ERAI & EBU & $\begin{array}{l}\text { CNRM-ALA- } \\
\text { DIN52 }\end{array}$ & IPSL-WRF311 & COSMO-CLM & ENEA-REGCM3 & $\begin{array}{l}\text { UCLM- } \\
\text { PROMES }\end{array}$ & CMCC-CCLM \\
\hline \multirow[t]{2}{*}{ Method 1} & \multirow[t]{2}{*}{14,141} & 17,613 & 14,626 & 15,646 & 15,613 & 17,563 & 13,976 & 18,661 \\
\hline & & 17,450 & 14,641 & 15,457 & 15,801 & 17,356 & - & - \\
\hline \multirow[t]{2}{*}{ Method 2} & \multirow[t]{2}{*}{1046} & 958 & 980 & 1071 & 990 & 1093 & 1361 & 999 \\
\hline & & 930 & 999 & 1093 & 1054 & 1053 & - & - \\
\hline \multirow[t]{2}{*}{ Method 3} & \multirow[t]{2}{*}{25,785} & 22,609 & 25,469 & 24,819 & 24,371 & 21,419 & 24,118 & 26,313 \\
\hline & & 22,382 & 25,478 & 24,947 & 24,376 & 21,400 & - & - \\
\hline \multirow[t]{2}{*}{ Method 4} & \multirow[t]{2}{*}{9674} & 8911 & 9359 & 10,022 & 10,337 & 9568 & 10,735 & 8742 \\
\hline & & 8947 & 9481 & 9971 & 10,323 & 9542 & - & - \\
\hline \multirow[t]{2}{*}{ Method 5} & \multirow[t]{2}{*}{8399} & 9717 & 9005 & 14,478 & 11,812 & 12,929 & 14,476 & 14,627 \\
\hline & & 9664 & 8923 & 14,424 & 11,909 & 13,032 & - & - \\
\hline \multirow[t]{2}{*}{ Method 6} & \multirow[t]{2}{*}{1170} & 1239 & 1432 & 1617 & 1831 & 2445 & 2770 & 1698 \\
\hline & & 1219 & 1394 & 1650 & 1871 & 2472 & - & - \\
\hline
\end{tabular}

distribution functions of cyclone maximum intensity. Lifetime and maximum intensity strongly depend on the applied cyclone tracking method. For instance, methods 2 and 4 tend to identify long lasting cyclone tracks (Fig. 3a) where approximately $30 \%$ of the tracked cyclones last more than 3 days. In contrast, the cyclones with lifetime of more than three days correspond to less than $20 \%$ of all cyclones detected by method 5 and about $5 \%$ of all cyclones detected by methods 1,3 and 6 . A plausible explanation for the variable cyclone lifetimes is the fact that different cyclone definitions by the tracking methods may result in capturing cyclones at different stages of their evolution. Concerning the cumulative distribution function of cyclones' maximum intensity (Fig. 3b), the intensities in the RVbased methods 1 and 2 are fairly equally distributed. For both methods the $20 \%$ of the most intense cyclones present $\mathrm{RV}$ values of more than $12 \times 10^{-5} \mathrm{~s}^{-1}$, while less than $20 \%$ of the tracked cyclones present intensities weaker than $6 \times 10^{-5} \mathrm{~s}^{-1}$. Also all SLP-based methods are in fair agreement. Minimum pressure for the $20 \%$ of the cyclones is less than $997 \mathrm{hPa}$ in methods 3 and 6 and in methods 4 and 5 is less than $1000 \mathrm{hPa}$. On the other hand, the $20 \%$ of the cyclones have core pressures of more than $1007 \mathrm{hPa}$ for methods 3 and 6 and more than $1010 \mathrm{hPa}$ for methods 4 and 5. It is noteworthy that by design method 3 detects cyclones as local SLP minima of less than $1013 \mathrm{hPa}$.

In this study we focus on the most intense Mediterranean cyclones, however the cyclones' intensity might be sensitive to the ERAI grid spacing, for both SLP and RVbased cyclone tracking methods (Murakami and Masato 2010; Kouroutzoglou et al. 2011). To avoid defining arbitrary thresholds on cyclone intensity and in order to analyze a statistically robust ensemble of intense Mediterranean cyclones, in this study we choose to analyze the 500 most intense cyclones from each method. We thus form a set of intense cyclones for ERAI and one for each RCM. These datasets each contain a total of 3000 intense cyclones (i.e., 500 cyclones from each cyclone tracking method). To simplify the analysis, we retain only the mature stage of the cyclones (the time and location of the track points with minimum SLP or maximum RV). Note that in each dataset the same cyclone may be detected by more than one method. We remove these multiples by considering that two cyclones are the same if their centers are located within no more than $3^{\circ}$ in longitude and latitude, and if both cyclones occur within a time difference of no more than $12 \mathrm{~h}$. This methodology to diagnose "identical" cyclone tracks is simpler than the one applied by Blender and Schubert (2000) or Froude et al. (2007), who used a criterion based on the whole cyclone tracks. However, here we treat a complex dataset with tracks reproduced from different methods and hence of different track characteristics (e.g., track lengths of the same cyclones might be considerably different; Fig. 3a). Removing multiples leads to 1600-1800 intense cyclone tracks per dataset (hereinafter referred to as the 500 most intense cyclones). Figure $3 \mathrm{c}$ shows the seasonal cycle of the 500 most intense cyclones in ERAI. All methods show a lower frequency of intense cyclones in summer and a higher one in spring and winter, in agreement with previous studies of intense Mediterranean cyclones (e.g., Campins et al. 2011; Cavicchia et al. 2014; Flaounas et al. 2015b).

\section{Cyclone tracks in the MED-CORDEX models}

\subsection{Assessment of RCMs to reproduce cyclone climatology in the Mediterranean region}

In order to assess the RCMs capacity to reproduce the Mediterranean cyclone climatology, we first calculate the CCD 
Fig. 3 Cyclone track characteristics with respect to the applied cyclone tracking method. a Cumulative distribution function of the cyclone lifetimes. b Cumulative distribution function of the cyclone intensities. RV-based methods 1 and 2 refer to the right axis, SLP-based methods 3-6 refer to the left axis. Note that the strongest cyclones are represented in the RV-based methods by the highest percentiles and in the SLPbased methods by the lowest percentiles. c Seasonal cycle of the occurrence of the 500 most intense cyclones
(A) Life-time

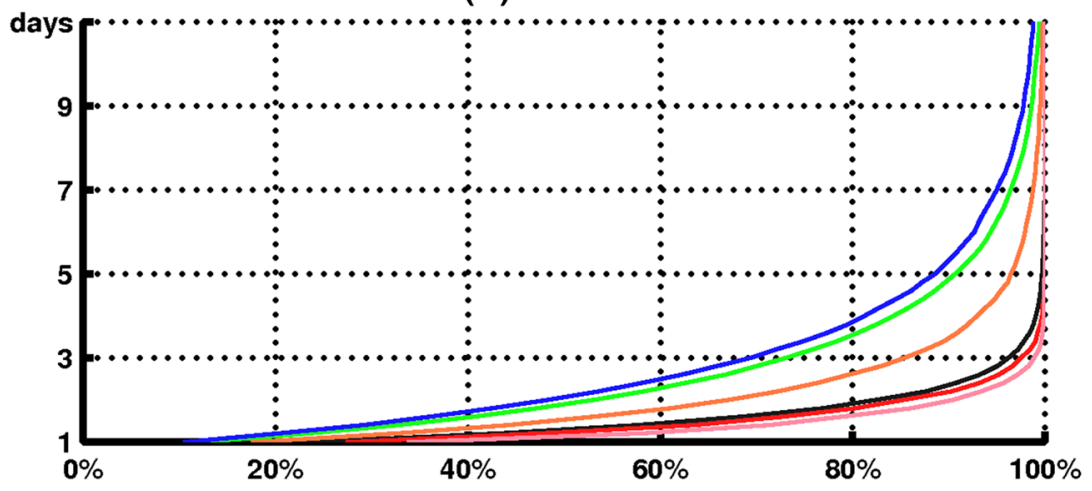

(B) Intensity

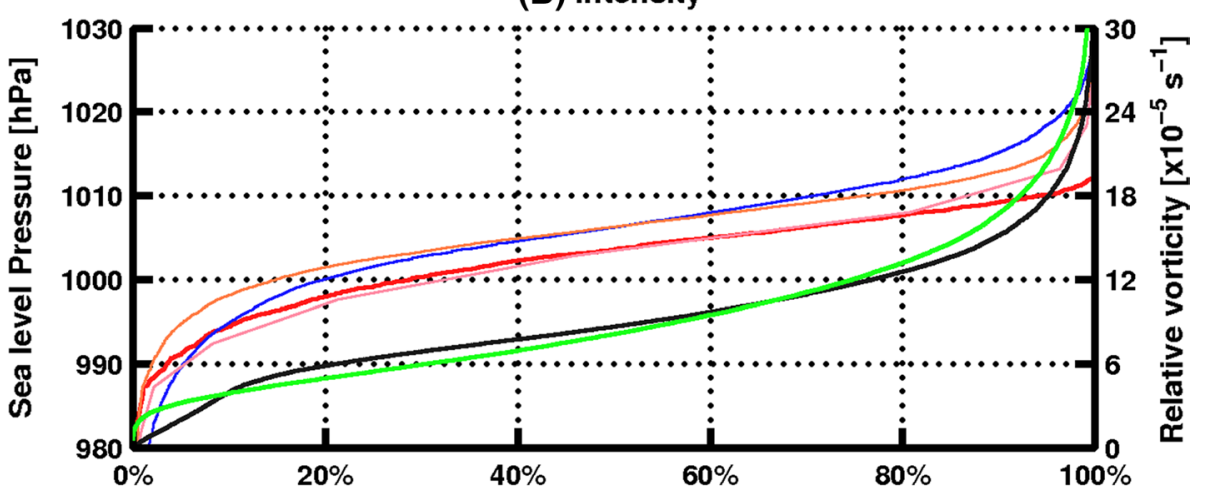

(C) $\mathbf{5 0 0}$ most intense cyclones

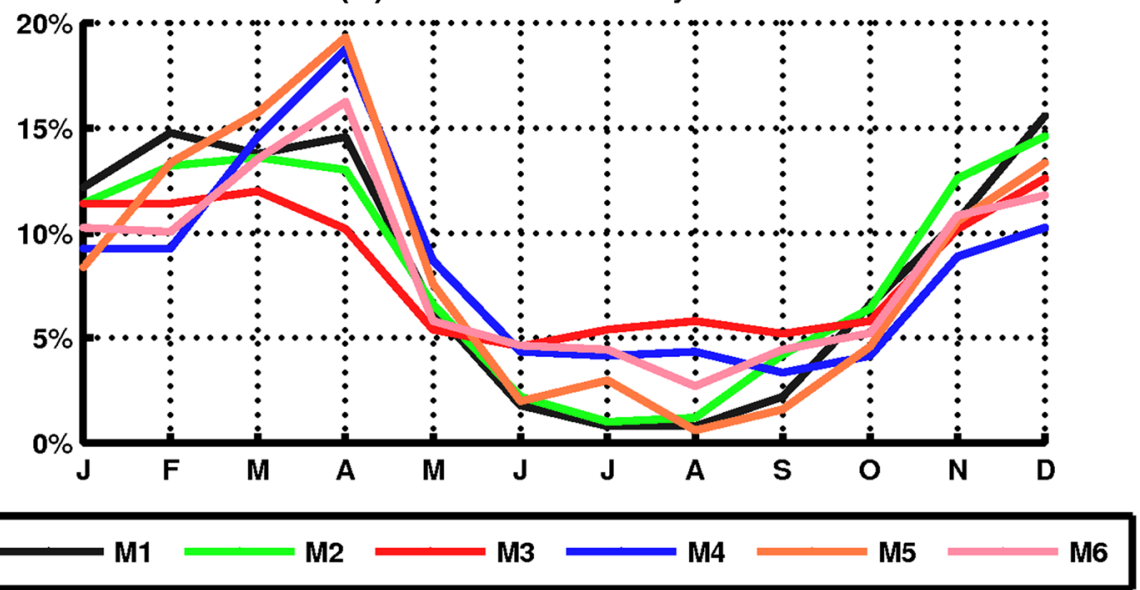

of each RCM and then compare it to the CCD of ERAI (Fig. 2). Online Resources 1 presents the CCD through the perspective of each cyclone tracking method and for each RCM. Compared to ERAI (Fig. 2), all RCMs tend to capture the main regions of frequent cyclogenesis (near the Alps, over the Adriatic, Ionian and Aegean Seas and the marine areas close to Cyprus). To statistically quantify the RCMs performance, Fig. 4 shows Taylor diagrams (Taylor 2001) that compare the CCD of the RCMs with regards to the CCD of ERAI, i.e., the CCDs as shown in Fig. 2 and in Online Resources 1, respectively. The correlation of the CCDs between the RCMs and ERAI is represented by the angle with the vertical axis, the corresponding centered root mean square error (RMSE) is represented by the distance from the black dot (representing ERAI), while the distance from the origin represents the standard deviation of the RCM (or ERAI). Since the CCD is not homogeneous in the region, the correlation, the RMSE and the standard deviation of each RCM reflect the models' capacity to properly represent the level and location of the regional 

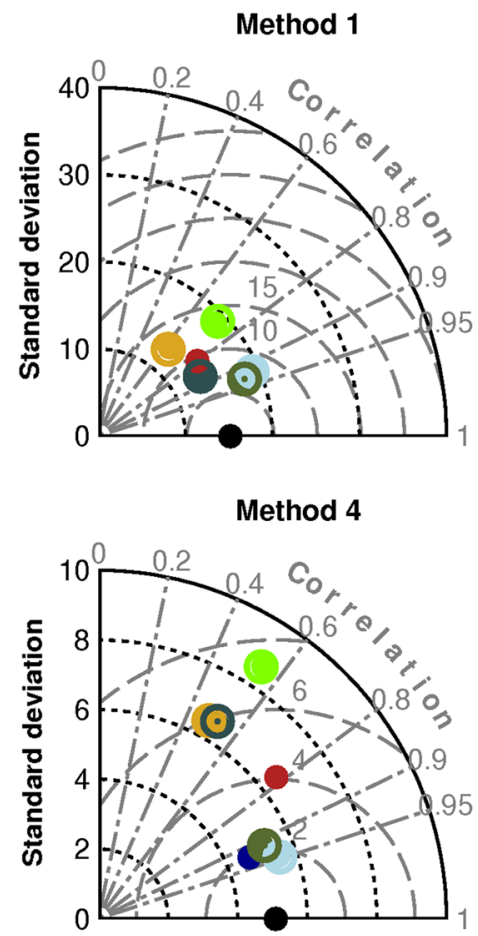
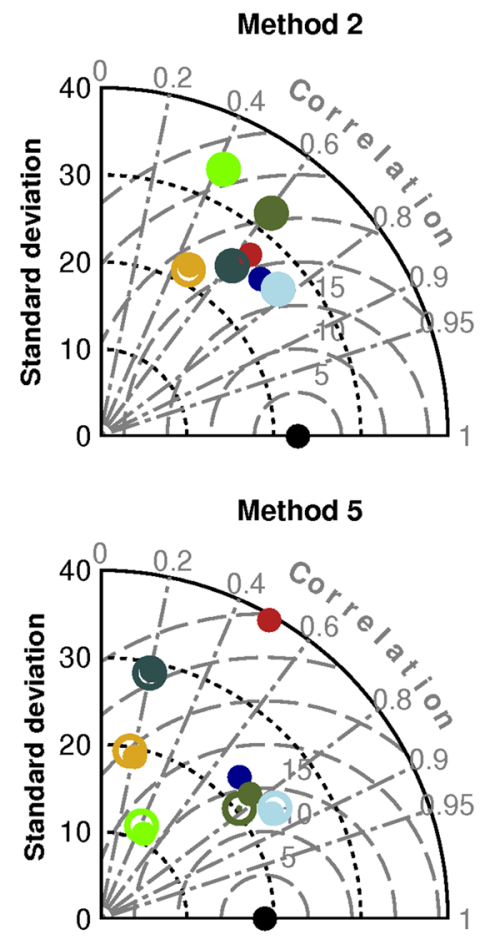
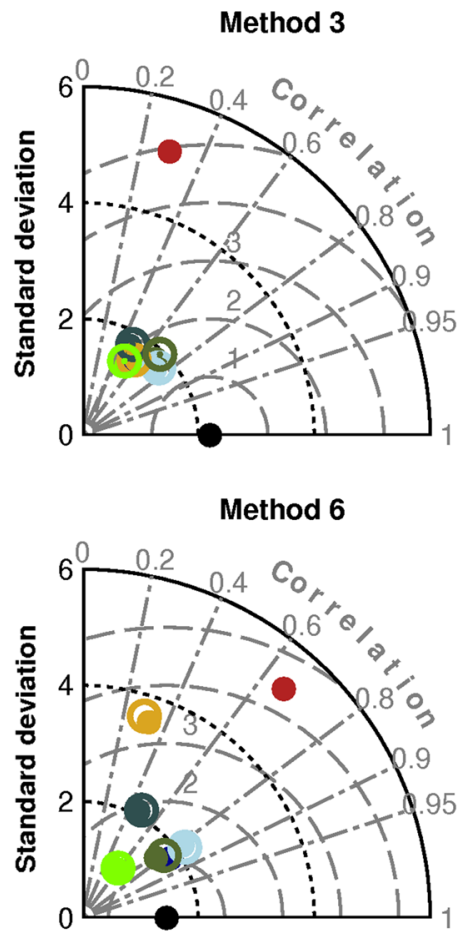

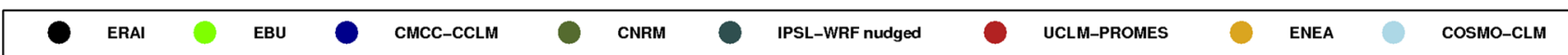

Fig. 4 Taylor diagrams for the spatial CCD comparison of all MED-CORDEX models (coupled simulations are shown in open circles), with respect to ERAI, as shown in Fig. 2 and in Online Resources 1. SD and RMSE are expressed in percent units

CCDs "hot spots" compared to ERAI. Several methods are sensitive to identifying cyclones close to the domain lateral boundaries, especially method 4 , and hence the analysis has been restricted to the region from $30^{\circ} \mathrm{N}$ to $46^{\circ} \mathrm{N}$ and from $5^{\circ} \mathrm{W}$ to $37.5^{\circ} \mathrm{E}$.

The results when using the RV-based methods 1 and 2 show that the RCMs present a small statistical spread (i.e., the models have similar values of the RMSE and standard deviation). The results of method 1 show that almost all RCMs have CCD RMSE values smaller than $15 \%$, standard deviations that are close to the reanalysis (about $15 \%$ ) and correlation scores between 0.6 and 0.95 . On the other hand, according to method 2, the RCMs present correlation scores between 0.4 and 0.8 , as well as RMSE values of more than $20 \%$. Methods 1 and 2 reproduce more cyclones than the other methods, reflecting their ability to also capture weak cyclonic circulations. The similar spread of RCMs when using these methods suggests that all models perform similarly in capturing these features. However, the poorer statistical scores for method 2, than for method 1 , are most likely due to very weak cyclones that are filtered out in method 1 (RV less than $3 \times 10^{-5} \mathrm{~s}^{-1}$ ) and which are expected to be less consistent between the RCMs and the reanalysis. Indeed, the reproduction of weak and small cyclones are expected to be particularly sensitive to model resolution and thus are expected to be more frequent in the cyclone climatology of RCMs than of ERAI.

Methods 3 and 6 detect the fewest cyclones (Table 2) and therefore the model comparison with ERAI in Fig. 4 reveals small RMSE and standard deviation values, compared to the other methods. A low RMSE does not imply that RCMs present "better" results when using these methods. In fact, the RMSE tends to provide relatively small values for weak and smooth fields (as the ones produced by methods 3 and 6 ) and tends to "punish" models that produce more variable fields with peaks at the wrong locations (the so-called double-penalty problem discussed in the verification literature, e.g., Wernli et al. 2008). In fact, for these methods, the CCD is higher over the Adriatic, Ionian and western Mediterranean seas (Fig. 2, Online resource 1), where the most intense cyclones are expected to occur (Flaounas et al. 2015b). Indeed, methods 3 and 6 apply a rather strong criterion on cyclone intensity, detecting only cyclones with SLP lower than $1013 \mathrm{hPa}$ and with a SLP gradient greater than $0.5 \mathrm{hPa}$ per $100 \mathrm{~km}^{-1}$, respectively. It is plausible thus to suggest that most of the RCMs capture correctly the occurrence of the most intense cyclones in the central Mediterranean. For methods 3 and 6 only UCLMPROMES (as well as ENEA-REGCM3 for method 6) does 
Table 3 Percentage of the 500 most intense cyclones, equally present in both ERAI and the MED-CORDEX models

\begin{tabular}{lllllll}
\hline EBU $(\%)$ & CNRM-ALADIN52 (\%) & IPSL-WRF311 (\%) & COSMO-CLM (\%) & ENEA-REGCM3 (\%) & UCLM-PROMES & CMCC-CCLM \\
\hline 33 & 40 & 63 & 44 & 24 & $29 \%$ & $36 \%$ \\
34 & 39 & 64 & 44 & 24 & - & - \\
\hline
\end{tabular}

Scores correspond to the uncoupled (first row in each cell) and coupled models (second row in each cell)

not present similar performance than the other RCMs, mainly due to their higher CCD close to the Alps.

While strong cyclones seem to be adequately captured by all RCMs (Fig. 2 and Online resource 1), method 5 presents a wide statistical spread in the RCMs performance. In fact, method 5 tends to capture the intense winter cyclones with closed contours of SLP and therefore similar statistical scores should be expected by all RCMs in Fig. 4. In contrast, method 5 presents the widest spread of the RCMs performance among the methods, with the COSMO-CLM, the CNRM and CMCC-CCLM having a similar CCD standard deviation as in ERAI (about $20 \%$ ) and the highest spatial correlation with the reanalysis. Further analysis suggests that the better statistical scores of these RCMs mostly reflect their capacity to capture the cyclones occurring close to the Alps, the Adriatic Sea and Cyprus. In these areas intense cyclones are most frequent and thus have a strong impact on statistical scores of method 5. Method 4 tends to smooth the CCD spatial variability over these areas (Fig. 2 and Online Resources 1) and hence it comes as no surprise that the COSMO-CLM, the CNRM and the CMCC-CCLM RCMs also present, as in method 5, the best performance compared to the other models.

Figure 4 shows that the coupled versions of the model simulations yield only small deviations of their statistical scores when compared with the atmosphere-only models. Online Resources 2 shows the CCD differences between the atmosphere-ocean coupled and uncoupled model versions. Indeed, the CCD differences exceed $5 \%$ for methods 1,2 and 5, while differences for methods 3,4 and 6 are less than $2 \%$. Such small CCD differences are supported by the fairly equal number of cyclone tracks between the coupled and uncoupled models, regardless of the method used (Table 2). Larger differences are shown in Online Resources 2 for method 5 close to the Turkish Aegean and southern coasts. This suggests that SST differences near these mountainous coasts may affect significantly the pattern of enclosing SLP contours and thus may modulate CCDs between coupled and uncoupled RCMs. This behavior of Method 5 in the eastern Mediterranean is observed for all RCMs.

\subsection{Intense cyclone climatologies in the RCMs}

In this section, we concentrate on the most intense cyclones. In order to assess the RCMs capacity to reproduce the same cyclones as in ERAI, we perform the same procedure as for filtering duplicate cyclones within the same cyclones dataset (Sect. 2.2). However, this time the filtering criteria are used to find equally reproduced cyclones between the RCMs and ERAI. Table 3 shows the percentage of ERAI intense cyclones reproduced by each RCM. Depending on the model, the similarity scores differ significantly between 24 and $40 \%$, suggesting that RCMs are able to reproduce about one third of the most intense ERAI cyclones. The IPSL-WRF311 model presents the best similarity score (of the order of $60 \%$ ) regardless of the cyclone tracking method used. This can be largely attributed to the application of grid nudging to the wind, temperature and water vapor fields above the planetary boundary layer (Omrani et al. 2013). This operation hinders this RCM to diverge from ERAI and therefore the high similarity score is a trivial consequence of nudging.

Figure 5 shows the CCD for the most intense cyclones only, as detected in ERAI (Fig. 5a) and in the uncoupled RCMs in the form of differences from ERAI (Fig. 5b-h). In accordance with previous studies, the most intense systems develop mainly over the western Mediterranean Sea (at the leeward side of the Alps), over the Adriatic and Ionian Seas, as well as over the Aegean and close to Cyprus (Fig. 5a). Surprisingly all RCMs, except WRF, underestimate the CCD of intense cyclones over the Mediterranean Sea. In contrast, the models tend to overestimate the frequency of intense cyclones over land, as for instance the ENEA-REGCM over the Balkans, and the CMCC-CCLM, WRF and PROMES RCMs close to the Alps. This suggests that the RCMs tend to produce more intense cyclones over land, and in particular close to the mountains. Therefore, fewer cyclones are found over the Mediterranean Sea in the dataset of the 500 most intense cyclones than in the reanalysis. Indeed, further analysis shows that if the 500 most intense cyclones in ERAI are compared to the 1500 most intense cyclones in RCMs (instead of the 500 most intense cyclones), then the RCMs similarity scores in Table 3 are higher by adding about $15 \%$ to each model score. In order to assess statistically the RCMs capacity to properly produce the climatology of intense cyclones, Fig. 6 shows a Taylor diagram for the CCDs of the RCMs compared to ERAI. Results show a similar performance for all RCMs, achieving a high correlation score of about 0.8 , similar standard deviations with ERAI and a RMSE of less than 


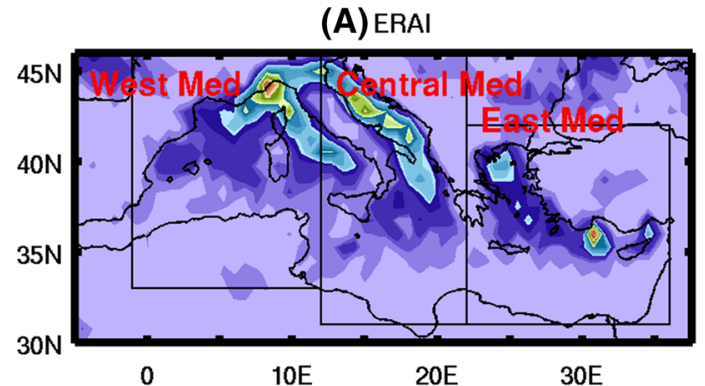

(C) CMCC-CCLM

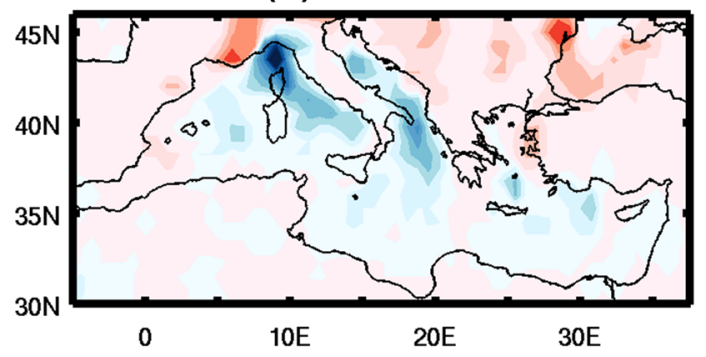

(E) IPSL-WRF nudged

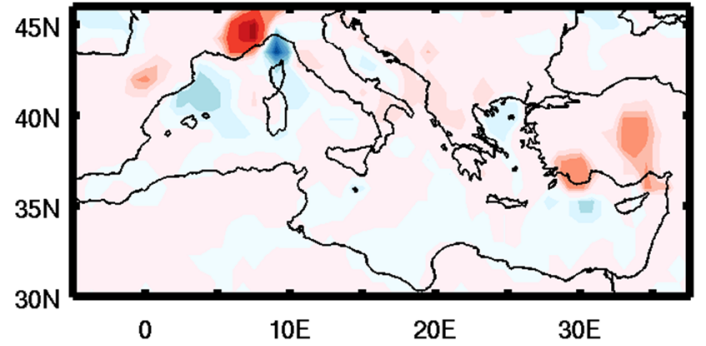

(G) ENEA-REGCM

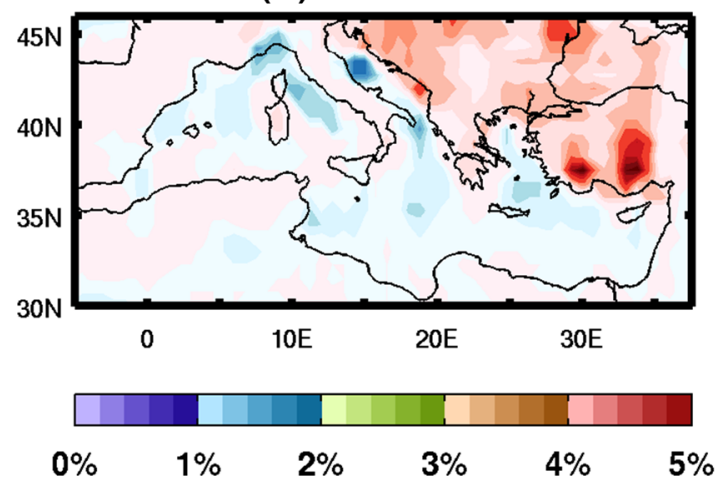

(B) EBU



(D) CNRM



(F) UCLM-PROMES

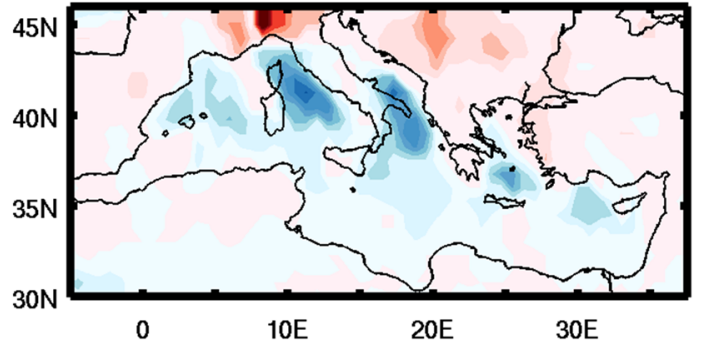

(H) CosMo-CLM

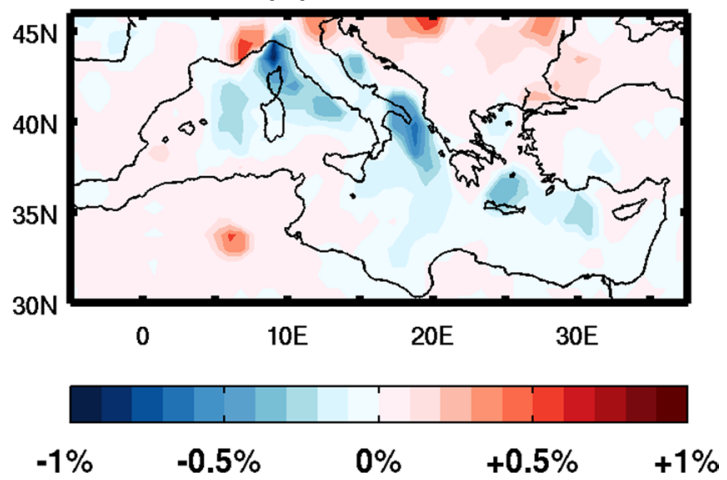

Fig. 5 a ERAI average cyclone center density of the 500 most intense cyclones from all six tracking methods during the period 1989-2008. B-h As a, but showing differences of each model from ERAI

$2 \%$. The exception is PROMES, which presents higher RMSE than the other RCMs, mainly due to the overestimation of CCD over the Alps and due to the underestimation of CCD in the marine areas near Italy.

To assess the models' capacity to reproduce the temporal variability of intense cyclones, we consider all intense cyclones forming in three different sub-regions: the western, central and eastern Mediterranean (boxes in Fig. 5a depict the three subregions). For each of the three subregions, we consider time series of the monthly counts of intense cyclones from 1989 to 2008. The results are shown in Fig. 7 in the form of Taylor diagrams, corresponding to the comparison of the cyclones inter-monthly variability between the RCMs and ERAI, in each of the three subregions, as well as in the whole Mediterranean domain. The small statistical spread of all models in Fig. 7 suggests 


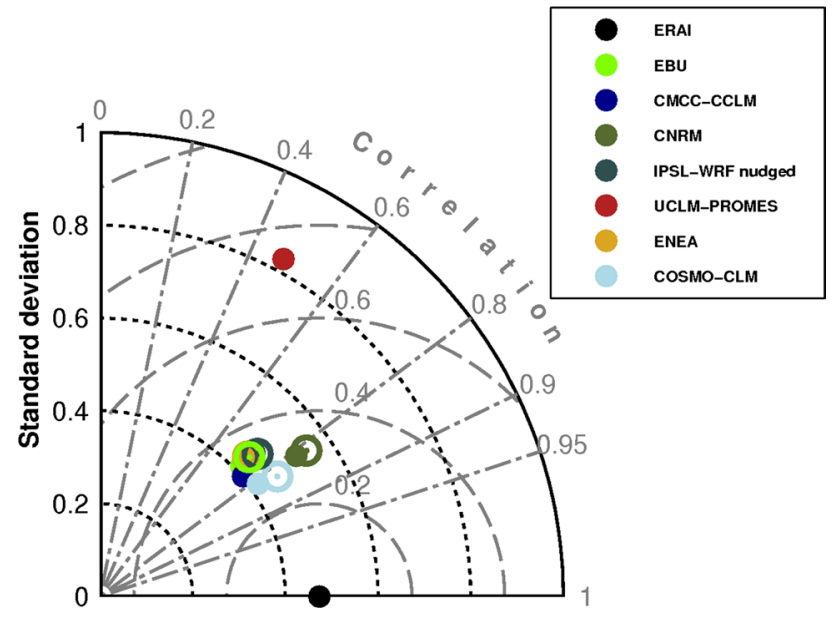

Fig. 6 As Fig. 4 but comparing for each model the CCD of the 500 most intense cyclones to ERAI. SD and RMSE are expressed in percent units

that the RCMs reproduce realistically the intense cyclones' seasonal cycle with minima of cyclone occurrences in summers and maxima in winter and spring (as shown in
Fig. 3c). Indeed, all models perform similarly, with correlation scores exceeding 0.6 and standard deviations close to ERAI. The ENEA RCM systematically presents higher RMSE than the other RCMs, while the RMSE of WRF is the lowest. The contrasting performance of ENEAREGCM and WRF is consistent with the lower and higher similarity scores of these RCMs in Table 3. The difference between the RMSE scores of the two RCMs is due to the good and poor skill in reproducing the cyclones seasonal cycle. In fact, the use of nudging in WRF benefits the RCM to reproduce realistically the ERAI intense cyclones (63\% similarity score; Table 3) and hence to better capture the cyclones' inter-monthly occurrence. On the other hand, the ENEA-REGCM presents about $25 \%$ of similar cyclones to ERAI and thus it is plausible to suggest that the rest of the cyclones are not following a consistent seasonal cycle as in ERAI. Indeed, further analysis shows that applying methods 4, 5 and 6, ENEA-REGCM tends to overestimate (underestimate) summer (winter) cyclone occurrences (not shown).

All RCMs present similar statistical scores for their coupled and uncoupled versions, whether if we consider
(A) Mediterranean

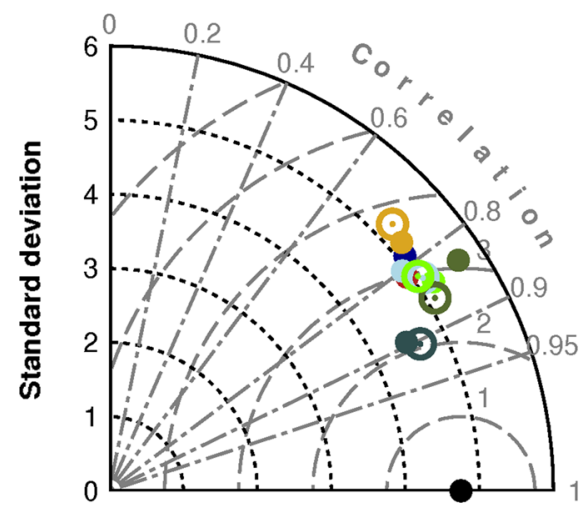

(C) Central Mediterranean

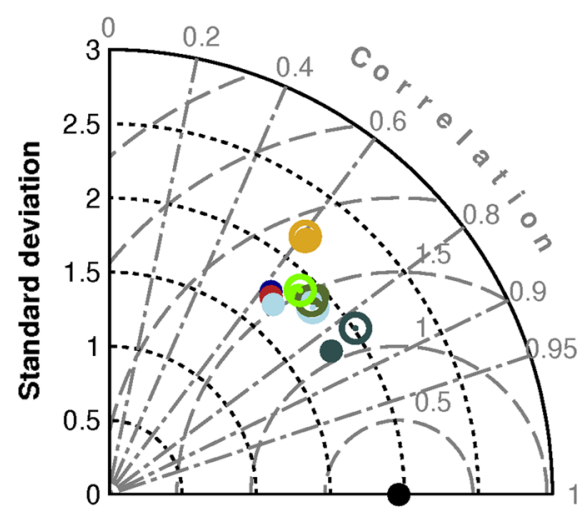

(B) West Mediterranean

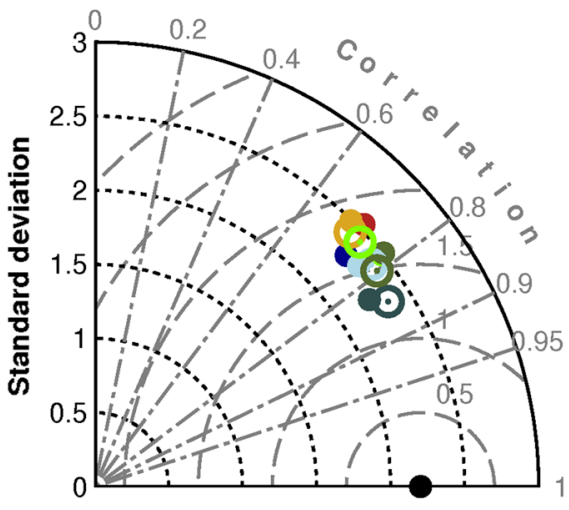

(D) East Mediterranean

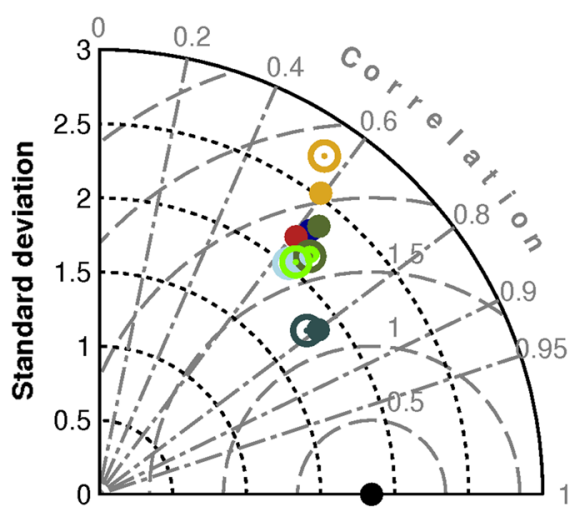

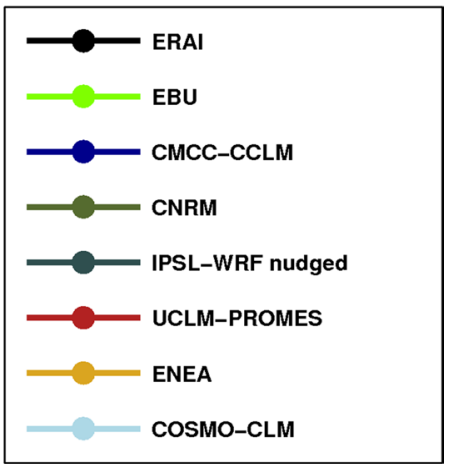

Fig. 7 Taylor diagrams comparing the RCMs time series of the monthly occurrence of the 500 most intense cyclones with respect to ERAI within the whole domain (a) and within each subregion (b-d) shown in Fig. 5a. SD and RMSE are expressed in number of cyclones per month 
Table 4 Percentage of the 500 most intense cyclones equally present in both atmospheric models and their coupled atmosphere-ocean versions

\begin{tabular}{lllll}
\hline EBU (\%) & $\begin{array}{l}\text { CNRM- } \\
\text { ALADIN52 } \\
(\%)\end{array}$ & $\begin{array}{l}\text { IPSL- } \\
\text { WRF311 }(\%)\end{array}$ & $\begin{array}{l}\text { COSMO- } \\
\text { CLM (\%) }\end{array}$ & $\begin{array}{l}\text { ENEA- } \\
\text { REGCM3 } \\
(\%)\end{array}$ \\
\hline 73 & 69 & 89 & 73 & 66 \\
\hline
\end{tabular}

all tracked cyclones (Fig. 4) or only the most intense ones (Figs. 6, 7). The small statistical differences between the cyclone climatologies in coupled and uncoupled RCMs suggest similar spatiotemporal variability of cyclone tracks. This is consistent with the results presented in Table 3, where fairly equal similarity scores are shown for both versions of the five coupled/uncoupled RCMs. In fact, when comparing intense cyclones between the coupled and uncoupled versions of the RCMs, the similarity scores increase dramatically. Table 4 shows that these scores might reach an average of more than $60 \%$, while the application of grid nudging in WRF results in the reproduction of $89 \%$ of similar cyclones between its coupled and uncoupled version. The weak contribution of air-sea coupling to the spatiotemporal occurrence of intense Mediterranean cyclones is however a rather expected result. Concerning intense cyclones, upper-tropospheric forcing from troughs and cut-off systems plays the primary role for their intensification (Fita et al. 2006; Claud et al. 2010; Flaounas et al. 2015b). The role of SST is certainly crucial in altering the baroclinicity at the lower atmospheric levels and therefore for affecting cyclones dynamics. However, the air-sea coupling effect in RCMs is associated with rapid air-sea exchanges that have an impact on the local scale patterns of SST rather than its seasonal and/or large scale distribution. Consequently it is unlikely that coupled models significantly affect atmospheric baroclinicity and/or synoptic scale systems and therefore play a crucial role for Mediterranean cyclones. This is supported by the results of Sanna et al. (2013) who used high-resolution coupled and uncoupled simulations to study the cyclone climatology in the Mediterranean. They used tracking method 4 and found significant differences between the two simulations only for short-lived cyclones with lifetimes of less than a day. Such cyclones have been however excluded in this study and would certainly correspond to weak systems.

Finally, we assess the RCMs capacity to reproduce realistically the intensity of the selected most intense cyclones. Figure 8 presents boxplots of cyclone intensity for each of the three sub-regions, for all RCMs and ERAI. Due to the different intensity metrics among the cyclone tracking methods, we separate RV-based methods 1 and 2 and SLP-based methods 3-6. Regardless of the sub-region, all intense cyclones in ERAI have SLP minima between
990 and $1005 \mathrm{hPa}$. Cyclones in the eastern Mediterranean tend to be weaker with a median of about $1000 \mathrm{hPa}$, compared to $997 \mathrm{hPa}$ for the western and central Mediterranean cyclones. In terms of RV, the ERAI cyclones in the eastern and the central Mediterranean tend to show fairly similar intensity distributions with median and extremes (95th percentile) reaching 17 and $22 \times 10^{-5} \mathrm{~s}^{-1}$, respectively, while western Mediterranean cyclones tend to be weaker with median and extremes of the order of 16 and $20 \times 10^{-5} \mathrm{~s}^{-1}$, respectively. For some RCMs, cyclone intensities in the RV-based methods are shown to be more intense in the Eastern Mediterranean, while they tend to be weaker if SLP-based methods are considered. A plausible explanation is the impact of orography to RCM resolved cyclone dynamics. More detailed orographic features may increase wind speeds and wind steering, resulting to higher RV at the cyclone centers, especially in the eastern Mediterranean domain, large part of which is covered by mountains. In all sub-regions, the ENEA, CMCC-CCLM and WRF RCMs distributions of SLP and RV are displaced to higher intensities with respect to ERAI, suggesting the production of more intense cyclones than in the reanalysis. On the other hand, the EBU, CNRM, COSMO-CLM RCMs present intensity distributions that are fairly close to ERAI in terms of median and extremes. It is noteworthy that PROMES presents more intense cyclones when considering their median of SLP, while in terms of RV its intensity distributions are closer to the ones of ERAI.

Again, the impact of air-sea coupling on cyclone intensity is rather insignificant for most models (Fig. 8). Significant differences between the structures of intensity distributions might be observed for specific models and sub-regions as for instance between the RV median of COSMO-CLM and ENEA-REGCM coupled and uncoupled versions (Fig. 8f). Thus, it seems that our results converge to the fact that the air-sea coupling effect is rather weak for the cyclones' spatiotemporal variability and intensities. In fact, the impact of SST to cyclone dynamics has been thoroughly investigated in past papers, where positive and negative SST anomalies have been applied (Homar et al. 2003; Katsafados et al. 2011; Miglietta et al. 2011; Tous et al. 2012). Results showed that when applying significant SST anomalies (e.g., +4 K) there were indeed considerable changes in cyclone dynamics and tracks. However, the coupled RCMs used here were shown to present an average SST bias of less than $1 \mathrm{~K}$ (Ruti et al. 2015) and therefore coupling could not be expected to have a strong impact on cyclones intensity. In addition, the weak impact of coupling air-sea interactions on cyclone intensity and tracks maybe due to the RCMs resolution. For instance, Akhtar et al. (2014) showed that the coupling effect in medicanes becomes significant for model grid spacings of the order of $10 \mathrm{~km}$, while it is rather weak for coarser grids. 
(A) West Mediterranean

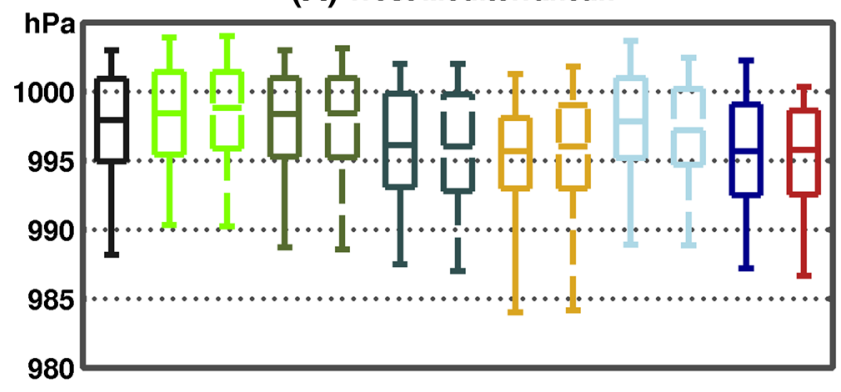

(C) Central Mediterranean



(E) East Mediterranean

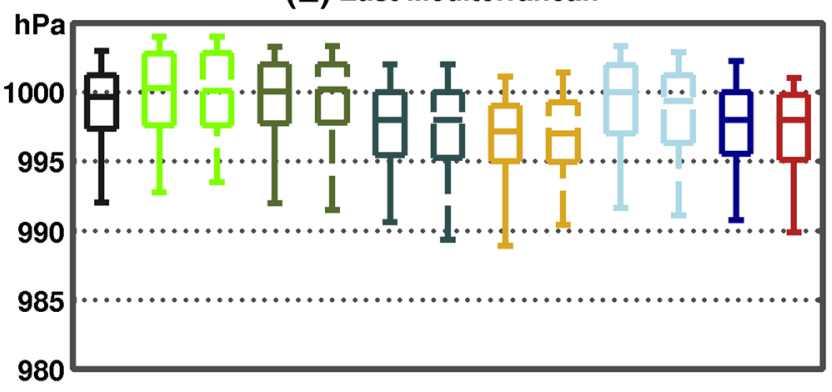

(B) West Mediterranean

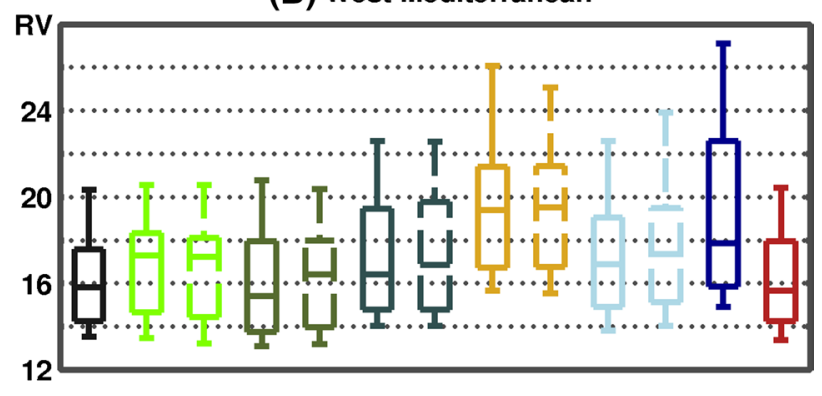

(D) Central Mediterranean

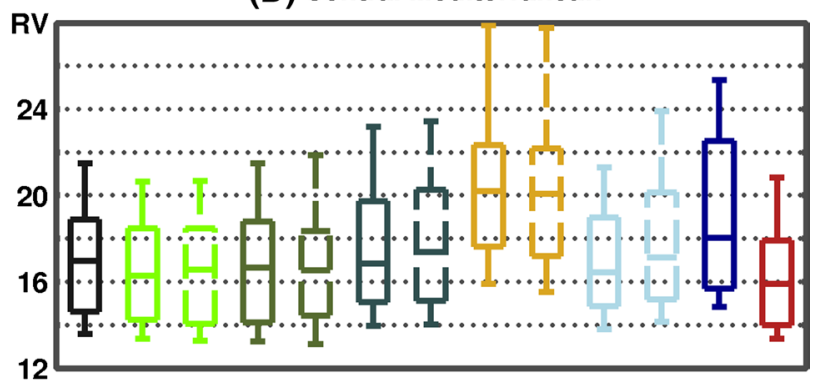

(F) East Mediterranean

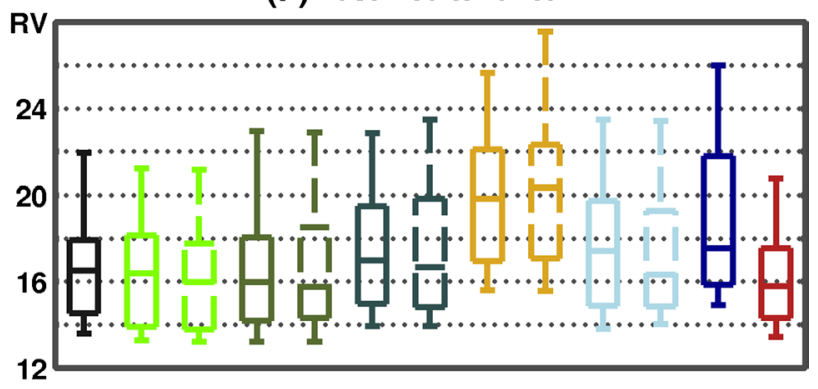

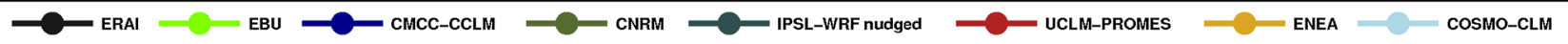

Fig. 8 Boxplots of the maximum intensity of the 500 most intense cyclones per subregion. Left panels consider only the SLP-based tracking methods and right panels only the RV-based tracking meth- ods. Boxplots drawn in dashed lines correspond to the coupled models. The boxes horizontal lines depict the 25 th, 50th and 75 th percentile, while whiskers depict the 5th and 95th percentile
Similar results have been reached by Gaertner et al. (this issue) who showed that improved horizontal resolution is important for RCMs to reproduce the most intense Mediterranean cyclones. It seems that the original resolution of the models (grid spacing of 20-50 km) is rather coarse for resolving realistically the feedback of air-sea interaction to cyclone dynamics.

\section{Summary and discussion}

In this study we analyzed the climatology of Mediterranean cyclones for the 20-year period of 1989-2008, as represented by ERAI and twelve RCM simulations. The simulations have been performed in the framework of the MED-CORDEX project by seven atmospheric RCMs. Five models were also coupled with an oceanic model. Our results are based on the application of six cyclone tracking methods, which emphasize different aspects of cyclone characteristics. Consequently, our study permits a wide assessment of the model's performance, covering multiple aspects of cyclone-related physics. This avoids false conclusions based upon a single, subjectively chosen analysis method.

The analysis of the tracks investigated the cyclones' spatial distribution, seasonal cycle and intensity evolution during their lifetime. Our main results are the following:

- Considering the RCMs capacity to realistically reproduce the climatology of Mediterranean cyclones, the interpretation of the results may vary according to the tracking method. With RV-based method 1, all RCMs 
have higher scores than with the RV-based method 2, which suggests that the RCMs tend to reproduce more accurately the stronger cyclones since the weaker ones are filtered out in method 1.

- Comparing the performance of RCMs using different SLP-based methods, the results become less homogeneous (Fig. 4). Methods 3 and 6, which tend to identify only the most intense cyclones, show a rather robust performance of all RCMs (except of PROMES and ENEA-REGCM, which have a relatively high RMSE). For methods 4 and 5, the RCMs COSMO-CLM, CNRM and CMCC-CCLM perform best with the lowest RMSE, high correlation scores and standard deviation equal to ERAI. The realistic reproduction of cyclones near the Alps is the key feature that determines the good performance of these $3 \mathrm{RCMs}$.

- Focusing on the most intense cyclones, all RCMs reproduce the spatial distribution of their tracks. However we show that the RCMs tend to produce more intense cyclones over land areas. It is noteworthy that RCMs have higher horizontal resolutions than ERAI and thus offer the potential of resolving finer scale atmospheric dynamics (e.g., related to interactions with orography). The feedback of fine scale atmospheric processes to meso-scale systems such as Mediterranean cyclones might have a non-detrimental effect on cyclone characteristics such as intensity and tracks. For instance, the RCMs tendency to produce more intense cyclones over land could be also attributed to the models' capacity to resolve more realistically, e.g., the impact of orography on cyclone dynamics. Consequently, our results concerning the reproduction of intense cyclones in the RCMs should not be regarded as a metric of the RCMs deficiency when compared to ERAI, but rather as the RCMs behavior when reproducing dynamics related to intense cyclones.

- Nudging is beneficial for reproducing the ERAI cyclones. Indeed, the WRF model, which used grid nudging reproduced about two thirds of ERAI intense cyclones, compared to the other RCMs that reproduced about one third. Grid nudging was also beneficial for WRF to perform closest to ERAI in terms of reproducing the cyclones' seasonal cycle. This performance of WRF, differing from the other RCMs, is due to the relaxation of its fields towards ERAI (for wind, temperature and water vapor), which in turn also served as our reference dataset. Therefore, for reasons of consistency the WRF nudged model could not be taken into account for a fair RCM intercomparison.

- Air-sea coupling was shown to have a rather weak impact on the cyclone climatology and their intensities. Concerning the cyclone climatology, the weak effect of air-sea interactions is explained by the fact that cyclo- genesis of intense cyclones is mainly due to upper tropospheric forcing. On the other hand, the weak effect of air-sea interactions on cyclone intensities could be due to the resolution of RCMs that is anyway coarser than what is typically needed to resolve such fine scale processes, as well as their feedback to the dynamics of the cyclonic systems.

Assessing the quality of RCMs reproduce prominent atmospheric flow systems such as cyclones is of paramount importance for understanding the model uncertainties in climate processes and extremes and this study shows the potential of tracking methods for a diagnostic description of RCM results. Though cyclone tracks are diagnostics on the spatiotemporal occurrence of cyclones and do not provide direct information on the complex multi-scale physical interactions that have a strong impact on cyclogenesis and cyclone intensification, they may be used to identify the factors responsible for the quality of RCMs results. The present work opens perspectives for the use of tracking methods to interpret RCMs outputs even beyond MEDCORDEX, not only for impact-related studies but also for Mediterranean cyclone dynamics.

Acknowledgments This work is part of the Med-CORDEX initiative (www.medcordex.eu). Med-CORDEX is a coordinated contribution to CORDEX that is supported by HyMeX (www.hymex. org) and MedCLIVAR (www.medclivar.eu) international programs. M.A. Gaertner and R. Romera were funded by the Spanish Government and the European Regional Development Fund, through Grants CGL2007-66440-C04-02, CGL2010-18013 and CGL2013-47261-R. S. Calmanti would like to acknowledge financial support from the EU funded SPECS project (Grant \# 3038378). N. Akhtar would like to thank the Center for Scientific Computing (CSC) of the Goethe University Frankfurt am Main and the Deutsches Klimarechenzentrum (DKRZ) for providing computational facilities. M.Reale in the last stage of this work was supported by OGS and CINECA under HPCTRES program award number 2015-07. Finally, H. Wernli would like to thank M. Sprenger for his help in adapting the cyclone tracking method 5 to data from regional models.

Open Access This article is distributed under the terms of the Creative Commons Attribution 4.0 International License (http://creativecommons.org/licenses/by/4.0/), which permits unrestricted use, distribution, and reproduction in any medium, provided you give appropriate credit to the original author(s) and the source, provide a link to the Creative Commons license, and indicate if changes were made.

\section{Appendix: Cyclone tracking methods}

Method 1-This method is performed in two distinct steps: In step I, all cyclonic centers are identified and located at each 6-hourly model output, for the whole period 19892008. Cyclone centers are defined as local maxima of RV 
within enclosed contours of $3 \times 10^{-5} \mathrm{~s}^{-1}$. The RV fields were first smoothed by applying a spatial moving average in an area of $8.25 \mathrm{deg}^{2}$ (i.e., $5 \times 5$ grid points). Tracking is then performed (step II) by connecting the identified cyclonic centers at consecutive time steps. This process is done by starting from the cyclonic center that presents the highest value of RV and then searches backward and forward in time for all possible tracks within a $10^{\circ} \times 5^{\circ}$ area in longitude and latitude. This process creates several candidate tracks associated with the same mature cyclonic state, i.e., the same track point of highest RV. The algorithm finally chooses the track that presents the least average difference of RV between consecutive track points, weighted by the distance between the track points. This tracking method is presented in detail in Flaounas et al. (2014).

Method 2-In this method the cyclone centers are first defined as local maxima of the RV field at $850 \mathrm{hPa}\left(\zeta_{850}\right)$ within a radius of $380 \mathrm{~km}$, determined every $6 \mathrm{~h}$ from the model output. Before determining the maxima, a 9 grid point spatial filter is applied on the $\zeta_{850}$ field, by weighting by the inverse of the distance from the central point. In a second step, trajectories are built by pairing the cyclone centers previously determined for consecutive time steps. Three criteria are used to connect the cyclone centers: (1) the first criterion takes into account the absolute vorticity field and its variation from the given cyclone center. If the variation between two cyclone centers is larger than $40 \%$, the two centers are considered to belong to two different cyclonic systems. (2) The second criterion uses the mean flow in the middle troposphere represented by wind at $700 \mathrm{hPa}$. From winds at 850 and $700 \mathrm{hPa}$ levels, two trajectory positions are determined and compared. (3) The third criterion ensures the trajectory coherence by minimizing the acceleration, in order to avoid the abrupt changes in wind speed and direction of the movement. More insight into this method is given in Ayrault and Joly (2000).

Method 3-This method functions in two steps too. First the cyclone centers are identified in each time step for the whole period, then they are connected by the tracking algorithm. The identification is based on finding minima in the SLP field. The SLP minima are searched successively in $15 \times 15$ grid point regions, which approximately corresponds to the typical size of a cyclone. A minimum is only kept, if it is less than $1013.5 \mathrm{hPa}$. The tracking algorithm uses the nearest neighbour approach. It specifies a rectangular area as a search region to find the continuation of the cyclone track in the consecutive time step. The search area is positioned around the cyclone center in a way that it is more extended on the eastern side. In this way the mainly eastward propagation of the cyclones is taken into account. If the algorithm finds more centers in the search area, the nearest one will be selected as the continuation of the track. At the end of the tracking procedure the cyclones lasting less than one day are discard. This tracking method is presented in detail in Kelemen et al. (2015).

Method 4-This method (Lionello et al. 2002) involves the partitioning of the SLP gridded fields in depressions by the identification of sets of steepest descent paths leading to the same SLP minimum. All the points crossed by a path leading to the same minimum are assigned to the same depression. Small depressions whose central minimum is close to the boundary of a different and deeper depression are included in the latter (a minimum distance has to be adjusted according to the grid spacing). This procedure attributes every point in the grid to a cyclone, such that the whole domain is divided in partitions, one for each cyclone center. The position of the SLP minimum is associated to the average position of all points in its partition with SLP not more than $3 \mathrm{hPa}$ higher than the actual minimum. A vicinity criterion is used for obtaining the trajectory associated with each cyclone by joining the location of low pressure centers in successive maps.

Method 5-This method identifies and tracks cyclones using a slightly refined variant of the method described in Wernli and Schwierz (2006). For every local minimum of the SLP field, isobars are considered at $0.5 \mathrm{hPa}$ intervals between 920 and $1050 \mathrm{hPa}$ and then the regions within closed isobars are accepted as cyclone regions. The maximum length of the enclosing contour is limited to $7500 \mathrm{~km}$, to exclude unrealistically large features that typically occur with very flat SLP distributions. Where SLP contours reach the border of the considered model domain, the contours are continued along the domain border. If two local SLP minima occur within a distance of less than $300 \mathrm{~km}$, they are merged and the system is regarded as a single multicenter cyclone. The tracking then tries to meaningfully connect the previously identified cyclone centers in time, as described in Wernli and Schwierz (2006) and with the following modifications: (1) no orography filter is used here because of the complex geography of the Mediterranean region (i.e., all SLP minima are considered as potential cyclone centers for the tracking), and (2) if a cyclone track cannot be continued for one or two time steps (e.g., because the cyclone transforms into an open wave structure without clouds SLP contours) then the track is continued in case that a reasonable candidate can be found after these time steps.

Method 6-This method comprises several steps. First, all relative minima of SLP are identified. A pressure gradient threshold is applied, such that only those lows exceeding a pressure gradient of $0.5 \mathrm{hPa} / 100 \mathrm{~km}$ along at least six of eight main directions (N, NE, E, SE, S, SW, W, NW) are retained. A size limitation is applied if two minima are within approximately $170 \mathrm{~km}$, such that only the minimum with the largest circulation is taken. In order to obtain cyclone tracks, the wind at $700 \mathrm{hPa}$ is taken as the steering 
wind for cyclones. A cyclone center is considered to follow another one in the previous time step if it is within an ellipse around the latter center and whose major axis is proportional to the speed of the steering wind. If several centers satisfy this, the one with a track direction closest to the $700 \mathrm{hPa}$ wind direction is selected as the next track point. Further details on the method are described in Picornell et al. (2001).

\section{References}

Akhtar N, Brauch J, Dobler A, Béranger K, Ahrens B (2014) Medicanes in an ocean-atmosphere coupled regional climate model. Nat Hazards Earth Syst Sci 14:2189-2201. doi:10.5194/ nhess-14-2189-2014

Alpert P, Neeman BU, Shay-El Y (1990) Climatological analysis of Mediterranean cyclones using ECMWF data. Tellus A 42(1):65-77

Ammar K, El-Metwally M, Almazroui M, Wahab MMA (2014) A climatological analysis of Saharan cyclones. Clim Dyn 43:483501. doi:10.1007/s00382-013-2025-0

Artale V, Calmanti S, Carillo A, Dell'Aquila A, Herrmann M, Pisacane G, PROTHEUS Group (2010) An atmosphere-ocean regional climate model for the Mediterranean area: assessment of a present climate simulation. Clim Dyn 35(5):721-740

Ayrault F, Joly A (2000) Une nouvelle typologie des dépresssions météorologiques: classification des phases de maturation. Compte-Rendus à l'Académie des Sciences, Sciences de la Terre et des planètes 330:167-172

Bartholy J, Pongracz R, Pattanyus-Abraham M (2009) Analysing the genesis, intensity and tracks of western Mediterranean cyclones. Theor Appl Climatol 96:133-144

Blender R, Schubert M (2000) Cyclone tracking in different spatial and temporal resolutions. Mon Weather Rev 128:377-384

Calmanti S, Dell'Aquila A, Maimone F, Pelino V (2015) Evaluation of climate patterns in a regional climate model over Italy using long-term records from SYNOP weather stations and cluster analysis. Clim Res 62:173-188

Campins J, Genovés A, Picornell MA, Jansà A (2011) Climatology of Mediterranean cyclones using the ERA-40 dataset. Int J Climatol 31:1596-1614. doi:10.1002/joc. 2183

Cavicchia L, von Storch H, Gualdi S (2014) A long-term climatology of medicanes. Clim Dyn 43:1183-1195

Christensen OB, Gaertner MA, Prego JA, Polcher J (2001) Internal variability of regional climate models. Clim Dyn 17:875-887

Claud C, Alhammoud B, Funatsu BM, Chaboureau JP (2010) Mediterranean hurricanes: large-scale environment and convective and precipitating areas from satellite microwave observations. Nat Hazards Earth Syst Sci 10:2199-2213. doi:10.5194/ nhess-10-2199-2010

Clough SA, Shephard MW, Mlawer EJ, Delamere JS, Iacono MJ, Cady-Pereira K, Boukabara S, Brown PD (2005) Atmospheric radiative transfer modeling: a summary of the AER codes. J Quant Spectrosc Radiat Transf 91:233-244

Colin J, Déqué M, Radu R, Somot S (2010) Sensitivity study of heavy precipitations in limited area model climate simulation: influence of the size of the domain and the use of the spectral nudging technique. Tellus A 62(5):591-604. doi:10.1111/j.1600-0870.2010.00467.x

D’Onofrio D, Palazzi E, von Hardenberg J, Provenzale A, Calmanti S (2014) Stochastic rainfall downscaling of climate models. J Hydrometeorol 15(2):830-843
Dee DP, Uppala SM, Simmons AJ, Berrisford P, Poli P, Kobayashi S, Andrae U, Balmaseda MA, Balsamo G, Bauer P, Bechtold P, Beljaars ACM, van de Berg L, Bidlot J, Bormann N, Delsol C, Dragani R, Fuentes M, Geer AJ, Haimberger L, Healy SB, Hersbach H, Hólm EV, Isaksen L, Kållberg P, Köhler M, Matricardi M, McNally AP, Monge-Sanz BM, Morcrette JJ, Park BK, Peubey C, de Rosnay P, Tavolato C, Thépaut JN, Vitart F (2011) The ERA-Interim reanalysis: configuration and performance of the data assimilation system. Q J R Meteorol Soc 137:553-597. doi:10.1002/qj.828

Deque M, Piedelievre JP (1995) High resolution climate simulation over Europe. Clim Dyn 11:321-339

Di Luca A, Flaounas E, Drobinski P, Brossier C (2014) The atmospheric component of the Mediterranean Sea water budget in a WRF multi-physics ensemble and observations. Clim Dyn 43(9-10):2349-2375

Djurdjevic V, Rajkovic B (2008) Verification of a coupled atmosphere-ocean model using satellite observations over the Adriatic Sea. Ann Geophys 26(7):1935-1954. doi:10.5194/ angeo-26-1935-2008

Domínguez M, Gaertner MA, De Rosnay P, Losada T (2010) A regional climate model simulation over West Africa: parameterization tests and analysis of land-surface fields. Clim Dyn 35(1):249-265

Drobinski P, Anav A, Lebeaupin Brossier C, Samson G, Stéfanon M, Bastin S, Baklouti M, Béranger K, Beuvier J, Bourdallé-Badie R, Coquart L, D'Andrea F, De Noblet-Ducoudré N, Diaz F, Dutay JC, Ethe C, Foujols AM, Khvorostyanov D, Madec G, Mancip M, Masson S, Menut L, Palmieri J, Polcher J, Turquety S, Valcke S, Viovy N (2012) Model of the regional coupled earth system (morce): application to process and climate studies in vulnerable regions. Environ Model Soft 35:1-18

Fita L, Romero R, Ramis C (2006) Intercomparison of intense cyclogenesis events over the Mediterranean basin based on baroclinic and diabatic influences. Adv Geosci 7:333-342. doi:10.5194/ adgeo-7-333-2006

Fita L, Romero R, Luque A, Emanuel K, Ramis C (2007) Analysis of the environments of seven Mediterranean tropical-like storms using an axisymmetric, nonhydrostatic, cloud resolving model. Nat Hazards Earth Syst Sci 7:41-56. doi:10.5194/nhess-7-41-2007

Flaounas E, Bastin S, Janicot S (2011) Regional climate modelling of the 2006 West African monsoon: sensitivity to convection and planetary boundary layer parameterisation using WRF. Clim Dyn 36:1083-1105

Flaounas E, Drobinski P, Bastin S (2013) Dynamical dowscaling of IPSL-CM5 CMIP5 historical simulations over the Mediterranean: benefits on the representation of regional surface winds and cyclogenesis. Clim Dyn 40:2497-2513. doi:10.1007/ s00382-012-1606-7

Flaounas E, Kotroni V, Lagouvardos K, Flaounas I (2014) CycloTRACK (v1.0)-tracking winter extratropical cyclones based on relative vorticity: sensitivity to data filtering and other relevant parameters. Geosci Model Dev 7:1841-1853. doi:10.5194/gmd-7-1841-2014

Flaounas E, Di Luca A, Drobinski P, Mailler S, Arsouze T, Bastin S, Beranger K, Lebeaupin Brossier C (2015a) Cyclone contribution to the Mediterranean Sea water budget. Clim Dyn 44:1-15. doi:10.1007/s00382-015-2622-1

Flaounas E, Raveh-Rubin S, Wernli H, Drobinski P, Bastin S (2015b) The dynamical structure of intense Mediterranean cyclones. Clim Dyn 44:2411-2427. doi:10.1007/s00382-014-2330-2

Froude LSR, Bengtsson L, Hodges KI (2007) The predictability of extratropical storm tracks and the sensitivity of their prediction to the observing system. Mon Weather Rev 135:315-333

Gaertner MA, Jacob D, Gil V, Domínguez M, Padorno E, Sánchez E, Castro M (2007) Tropical cyclones over the Mediterranean Sea 
in climate change simulations. Geophys Res Lett 34:L14711. doi:10.1029/2007GL029977

Gaertner MA, González-Alemán JJ, Romera R, Domínguez M, Gil V, Sánchez E, Gallardo C, Miglietta MM, Walsh K, Sein D, Somot S, Dell'Aquila A, Teichmann C, Ahrens B, Buonomo E, Colette A, Bastin S, van Meijgaard E, Nikulin G (this issue) Simulation of medicanes over the Mediterranean Sea in a regional climate model ensemble: impact of ocean-atmosphere coupling and increased resolution

Giorgi F (1990) Simulation of regional climate using a limited area model nested in a general circulation model. J Climate 3:941-963

Giorgi F, Mearns LO (1999) Introduction to special section: regional climate modeling revisited. J Geophys Res Atmos 104(D6):6335-6352

Giorgi F, Jones C, Asrar G (2009) Addressing climate information needs at the regional level: the CORDEX framework. WMO Bull 58:175-183

Guyennon N, Romano E, Portoghese I, Salerno F, Calmanti S, Petrangeli AB, Copetti D (2013) Benefits from using combined dynamical-statistical downscaling approaches-lessons from a case study in the Mediterranean region. Hydrol Earth Syst Sci 17:705-720

Hanley J, Caballero R (2012) Objective identification and tracking of multicentre cyclones in the ERA-Interim reanalysis dataset. Q J R Meteorol Soc 138:612-625. doi:10.1002/qj.948

Herrmann M, Somot S, Calmanti S, Dubois C, Sevault F (2011) Representation of daily wind speed spatial and temporal variability and intense wind events over the Mediterranean Sea using dynamical downscaling: impact of the regional climate model configuration. Nat Hazards Earth Syst Sci 11:1983-2001. doi:10.5194/nhess-11-1983-2011

Homar V, Romero R, Stensrud DJ, Ramis C, Alonso S (2003) Numerical diagnosis of a small, quasi-tropical cyclone over the western Mediterranean: dynamical vs. boundary factors. Q J R Meteorol Soc 129:1469-1490. doi:10.1256/qj.01.91

Hong SY, Dudhia J, Chen SH (2004) A revised approach to ice microphysical processes for the bulk parameterization of clouds and precipitation. Mon Weather Rev 132:103-120

Hoskins BJ, Hodges KI (2002) New perspectives on the Northern Hemisphere winter storm tracks. J Atmos Sci 59:1041-1061

Jansà A, Genovés A, Picornell MA, Campins J, Riosalido R, Carretero O (2001) Western Mediterranean cyclones and heavy rain. Part 2: Statistical approach. Meteorol Appl 8:43-56

Kain JS (2004) The Kain-Fritsch convective parameterization: an update. J Appl Meteorol 43:170-181

Katsafados P, Mavromatidis E, Papadopoulos A, Pytharoulis I (2011) Numerical simulation of a deep Mediterranean storm and its sensitivity on sea surface temperature. Nat Hazards Earth Syst Sci 11:1233-1246. doi:10.5194/nhess-11-1233-2011

Kelemen FD, Bartholy J, Pongracz R (2015) Multivariable cyclone analysis in the Mediterranean region. Idojaras Q J Hung Meteorol Serv 119(2):159-184

Kouroutzoglou J, Flocas HA, Simmonds I, Keay K, Hatzaki M (2011) Assessing characteristics of Mediterranean explosive cyclones for different data resolution. Theor Appl Climatol 105(1-2):263-275

Krzic A, Tosic I, Djurdjevic V, Veljovic K, Rajkovic B (2011) Changes in some indices over Serbia according to the SRES A1B and A2 scenarios. Clim Res 49:73-86. doi:10.3354/cr01008

Lebeaupin Brossier C, Béranger K, Deltel C, Drobinski P (2011) The Mediterranean response to different space-time resolution atmospheric forcings using perpetual mode sensitivity simulations. Ocean Model 36(1):1-25

Lebeaupin Brossier C, Drobinski P, Béranger K, Bastin S, Orain F (2013) Ocean memory effect on the dynamics of coastal heavy precipitation preceded by a mistral event in the northwestern Mediterranean. Q J R Meteorol Soc 139(675):1583-1597

Lionello P, Giorgi F (2007) Winter precipitation and cyclones in the Mediterranean region: future climate scenarios in a regional simulation. Adv Geosci 12:153-158

Lionello P, Dalan F, Elvini E (2002) Cyclones in the Mediterranean region: the present and the doubled $\mathrm{CO}_{2}$ climate scenarios. Clim Res 22:147-159

Lionello P, Bhend J, Buzzi A, Della-Marta PM, Krichak SO, Jansa A, Maheras P, Sanna A, Trigo IF, Trigo R (2006) Cyclones in the mediterranean region: climatology and effects on the environment. In: Lionello P, Malanotte-Rizzoli P, Boscolo R (eds) Mediterranean climate variability, developments in earth and environmental sciences, vol 4. Elsevier, Amsterdam, pp 325-372

Lionello P, Trigo IF, Gil V, Liberato MLR, Nissen KM, Pinto JG, Raible CC, Reale M, Tanzarella A, Trigo RM, Ulbrich S, Ulbrich U (2016) Objective climatology of cyclones in the Mediterranean region: a consensus view among methods with different system identification and tracking criteria. Tellus A. doi:10.3402/tellusa. v68.29391

Llasat MC, Llasat-Botija M, Prat MA, Porću F, Price C, Mugnai A, Lagouvardos K, Kotroni V, Katsanos D, Michaelides S, Yair Y, Savvidou K, Nicolaides K (2010) High-impact floods and flash floods in Mediterranean countries: the FLASH preliminary database. Adv Geosci 23:47-55. doi:10.5194/adgeo-23-47-2010

Maheras P, Flocas HA, Patrikas I, Anagnostopoulou C (2001) A 40 year objective climatology of surface cyclones in the Mediterranean region: spatial and temporal distribution. Int $\mathrm{J}$ Climatol 21:109-130. doi:10.1002/joc.599

Marshall J, Adcroft A, Hill C, Perelman L, Heisey C (1997a) A finite volume, incompressible Navier Stokes model for studies of the ocean on parallel computers. J Geophys Res Oceans 102(C3):5753-5766

Marshall J, Hill C, Perelman L, Adcroft A (1997b) Hydrostatic, quasihydrostatic, and nonhydrostatic ocean modeling. J Geophys Res Oceans 102(C3):5733-5752

Miglietta MM, Moscatello A, Conte D, Mannarini G, Lacorata G, Rotunno R (2011) Numerical analysis of a Mediterranean 'hurricane' over south-eastern Italy: sensitivity experiments to sea surface temperature. Atmos Res 101:412-426. doi:10.1016/j. atmosres.2011.04.006

Murakami H, Masato S (2010) Effect of model resolution on tropical cyclone climate projections. Sola 6:73-76

Murray RJ, Simmonds I (1991) A numerical scheme for tracking cyclone centres from digital data. Part I: development and operation of the scheme. Aust Meteorol Mag 39:155-166. doi:10.1007/s00382-016-3398-7

Nabat P, Somot S, Mallet M, Sevault F, Chiacchio M, Wild M (2015) Direct and semi-direct aerosol radiative effect on the Mediterranean climate variability using a coupled regional climate system model. Clim Dyn 44:1127-1155. doi:10.1007/ s00382-014-2205-6

Neu U, Akperov MG, Bellenbaum N, Benestad R, Blender R, Caballero R, Cocozza A, Dacre HF, Feng Y, Fraedrich K, Grieger J, Gulev S, Hanley J, Hewson T, Inatsu M, Keay K, Kew SF, Kindem I, Leckebusch GC, Liberato MLR, Lionello P, Mokhov II, Pinto JG, Raible CC, Reale M, Rudeva I, Schuster M, Simmonds I, Sinclair M, Sprenger M, Tilinina ND, Trigo IF, Ulbrich S, Ulbrich U, Wang XL, Wernli H (2013) IMILAST: a community effort to intercompare extratropical cyclone detection and tracking algorithms. Bull Am Meteorol Soc 94:529-547. doi:10.1175/ BAMS-D-11-00154.1

Nissen KM, Leckebusch GC, Pinto JG, Renggli D, Ulbrich S, Ulbrich U (2010) Cyclones causing wind storms in the Mediterranean: characteristics, trends and links to large-scale patterns. Nat Hazards Earth Syst Sci 10:1379-1391. doi:10.5194/nhess-10-1379-2010 
Omrani H, Drobinski P, Dubos T (2013) Optimal nudging strategies in regional climate modelling: investigation in a Big-Brother experiment over the European and Mediterranean regions. Clim Dyn 41(9-10):2451-2470

Pal JS, Giorgi F, Bi X, Elguindi N, Solmon F, Gao X, Rauscher SA, Francisco R, Zakey A, Winter J, Ashfaq M (2007) Regional climate modeling for the developing world: the ICTP RegCM3 and RegCNET. Bull Am Meteorol Soc 88(9):1395

Picornell MA, Jansa A, Genovés A, Campins J (2001) Automated database of mesocyclones from the HIRLAM (INM)- $0.5^{\circ}$ analyses in the western Mediterranean. Int J Climatol 21(3):335-354

Pinto JG, Spangehl T, Ulbrich U, Speth P (2005) Sensitivities of a cyclone detection and tracking algorithm: individual tracks and climatology. Meteorol Z 14(6):823-838

Raveh-Rubin S, Wernli H (2015) Large-scale wind and precipitation extremes in the Mediterranean - a climatological analysis for 1979-2012. Q J R Meteorol Soc 141:2404-2417. doi:10.1002/ qj. 2531

Reale M, Lionello P (2013) Synoptic climatology of winter intense precipitation events along the Mediterranean coasts. Nat Hazards Earth Syst Sci 13:1707-1722. doi:10.5194/nhess-13-1707-2013

Rockel B, Geyer B (2008) The performance of the regional climate model CLM in different climate regions, based on the example of precipitation. Meteorol Z 17(4):487-498

Rockel B, Will A, Hense A (2008) The regional climate model COSMO-CLM (CCLM). Meteorol Z 17(4):347-348

Roeckner E, Brokopf R, Esch M, Giorgetta M, Hagemann S, Kornblueh L, Manzini E, Schlese U, Schulzweida U (2006) Sensitivity of simulated climate to horizontal and vertical resolution in the ECHAM5 atmosphere model. J Clim 19:3771-3791. doi:10.1175/JCLI3824.1

Romanski J, Romanou A, Bauer M, Tselioudis G (2012) Atmospheric forcing of the Eastern Mediterranean Transient by midlatitude cyclones. Geophys Res Lett 39:L03703. doi:10.1029/2 011 GL050298

Rudeva I, Gulev S, Simmonds I, Tilinina N (2014) The sensitivity of characteristics of cyclone activity to identification procedures in tracking algorithms. Tellus A 66:24961. doi:10.3402/tellusa. v66.24961

Ruti P, Somot S, Giorgi F, Dubois C, Flaounas E, Obermann A, Dell'Aquila A, Pisacane G, Harzallah A, Lombardi E, Ahrens B, Akhtar N, Alias A, Arsouze T, Aznar R, Bastin S, Bartholy J, Beranger K, Beuvier J, Bouffies-Cloche S, Brauch J, Cabos W, Calmanti S, Calvet JC, Carillo A, Conte D, Coppola E, Djurdjevic V, Drobinski P, Elizalde A, Gaertner M, Galan P, Gallardo C, Gualdi S, Goncalves M, Jorba O, Jorda G, Lheveder B, Lebeaupin-Brossier C, Li L, Liguori G, Lionello P, Macias-Moy D, Onol B, Rajkovic B, Ramage K, Sevault F, Sannino G, Struglia MV, Sanna A, Torma C, Vervatis V (2015) MED-CORDEX initiative for Mediterranean Climate studies. Bull Am Meteorol Soc. doi:10.1175/BAMS-D-14-00176.1

Sanchez-Gomez E, Somot S, Josey SA, Dubois C, Elguindi N, Déqué M (2011) Evaluation of the Mediterranean sea water and heat budgets as simulated by an ensemble of high resolution regional climate models. Clim Dyn 37:2067-2086. doi:10.1007/ s00382-011-1012-6
Sanchez-Gomez E, Somot S (2016) Impact of the internal variability on the cyclone tracks simulated by a regional climate model over the Med-CORDEX domain. Clim Dyn 1-17

Sanna A, Lionello P, Gualdi S (2013) Coupled atmosphere ocean climate model simulations in the Mediterranean region: effect of a high-resolution marine model on cyclones and precipitation. Nat Hazards Earth Syst Sci 13:1567-1577. doi:10.5194/ nhess-13-1567-2013

Sannino G, Herrmann M, Carillo A, Rupolo V, Ruggiero V, Artale V, Heimbach P (2009) An eddy-permitting model of the Mediterranean Sea with a two-way grid refinement at the Strait of Gibraltar. Ocean Model 30:56-72. doi:10.1061/j. ocemod.2009.06.2002

Sevault F, Somot S, Alias A, Dubois C, Lebeaupin-Brossier C, Nabat P, Adloff F, Déqué M, Decharme B (2014) A fully coupled Mediterranean regional climate system model: design and evaluation of the ocean component for the 1980-2012 period. Tellus A 66:23967. doi:10.3402/tellusa.v66.23967

Skamarock WC, Klemp JB (2008) A time-split nonhydrostatic atmospheric model for weather research and forecasting applications. J Comput Phys 227(7):3465-3485

Taylor KE (2001) Summarizing multiple aspects of model performance in a single diagram. J Geophys Res 106(D7):7183-7192. doi:10.1029/2000JD900719

Tous M, Romero R, Ramis C (2012) Surface heat fluxes influence on medicane trajectories and intensification. Atmos Res 123:400-411

Tramblay Y, Ruelland D, Somot S, Bouaicha R, Servat E (2013) High-resolution Med-Cordex regional climate model simulations for hydrological impact studies: a first evaluation of the ALADIN-Climate model in Morocco. Hydrol Earth Syst Sci 17:3721-3739. doi:10.5194/hess-17-3721-2013

Trigo IF, Davies TD, Bigg GR (1999) Objective climatology of cyclones in the Mediterranean region. J Clim 12:1685-1696. doi:10.1175/1520-0442(1999)012<1685:OCOCIT>2.0.CO;2

Trigo IF, Davies TD, Bigg GR (2000) Decline in Mediterranean rainfall caused by weakening of Mediterranean cyclones. Geophys Res Lett 27:2913-2916

Walsh K, Giorgi F, Coppola E (2014) Mediterranean warm-core cyclones in a warmer world. Clim Dyn 42:1053-1066

Wernli H, Schwierz C (2006) Surface cyclones in the ERA-40 dataset (1958-2001). Part I: Novel identification method and global climatology. J Atmos Sci 63:2486-2507

Wernli H, Paulat M, Hagen M, Frei C (2008) SAL—a novel quality measure for the verification of quantitative precipitation forecasts. Mon Weather Rev 136:4470-4487. doi:10.1175/2008 MWR2415.1

Zappa G, Hawcroft MK, Shaffrey L, Black E, Brayshaw DJ (2015) Extratropical cyclones and the projected decline of winter Mediterranean precipitation in the CMIP5 models. Clim Dyn. doi:10.1007/s00382-014-2426-8 (in press) 